\title{
Small Molecule Inhibitors of the Epidermal Growth Factor Receptor
}

\author{
M. Raymond V. Finlay and Richard A. Ward
}

\begin{abstract}
The epidermal growth factor receptor (EGFR) has emerged over the past two decades as a key target in therapeutic approaches to the treatment of non-small cell lung cancer (NSCLC). This chapter describes the evolution of the EGFR small molecule inhibitor field, from early exploratory work and growing insight into the role of EGFR activating mutations, through to the first approved therapies, gefitinib and erlotinib. Advances in understanding resistance to these initial therapies and the role of the T790M mutation are discussed, along with drug discovery efforts culminating in the discovery of a number of EGFR mutant selective inhibitors, including osimertinib (TAGRISSO ${ }^{\mathrm{TM}}$ ), the first approved treatment for patients with EGFR T790M mutation-positive metastatic NSCLC.
\end{abstract}

Keywords Irreversible inhibitor, Kinase, Mutant, Resistance, T790M

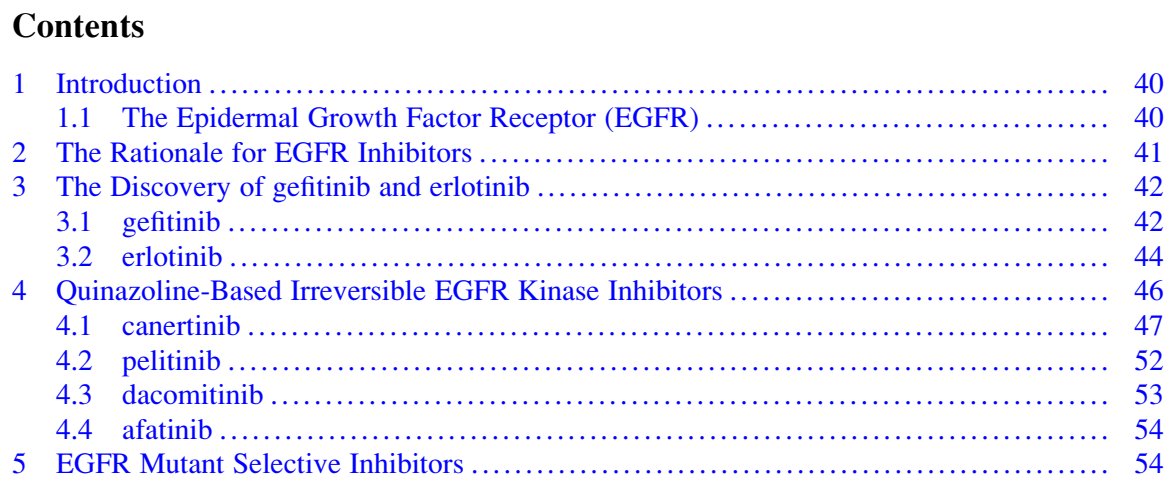

M.R.V. Finlay ( $\square)$ and R.A. Ward IMED Oncology, AstraZeneca, Darwin Building, 310 Cambridge Science Park, Milton Road, Cambridge CB4 0WG, UK

e-mail: ray.finlay@astrazeneca.com 


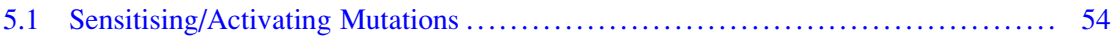

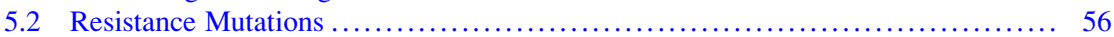

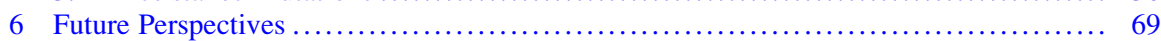

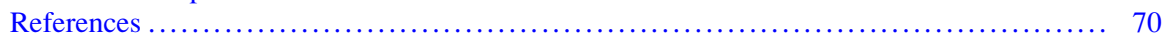

\section{Introduction}

Non-small cell lung cancer (NSCLC) remains a leading cause of human mortality in both the western and developing worlds [1]. Nevertheless, over the past two decades, considerable therapeutic progress has been made in the treatment of the disease by exploiting our growing understanding of the role of the epidermal growth factor receptor (EGFR) and its etiology in NSCLC.

\subsection{The Epidermal Growth Factor Receptor (EGFR)}

EGFR belongs to the erbB (erythroblastosis oncogene B) family of receptors [2, 3], which consists of four members (Fig. 1):

- ErbB-1, also known as epidermal growth factor receptor (EGFR) and HER1

- ErbB-2, also known as HER2 (human epidermal growth factor receptor 2) in humans

- ErbB-3, also known as HER3

- ErbB-4, also known as HER4

$\begin{array}{cccc}\text { ErbB1 } & \text { ErbB2 } & \text { ErbB3 } & \text { ErbB4 } \\ \text { EGFR, HER1 } & \text { HER2 } & \text { HER3 } & \text { HER4 }\end{array}$

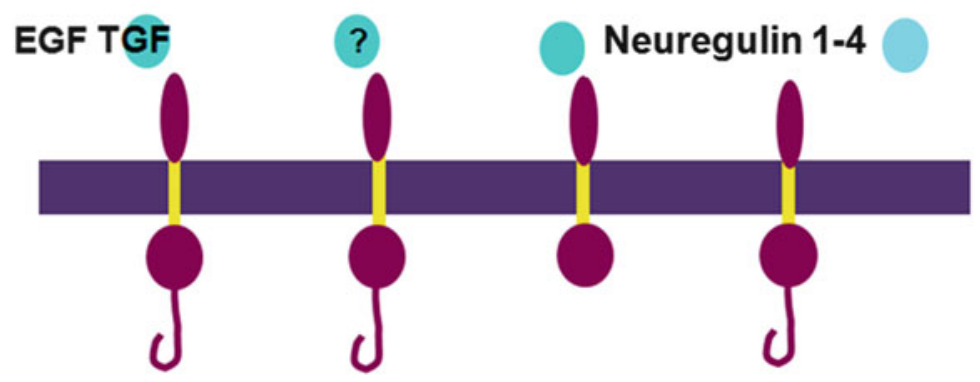

Fig. 1 ErbB family of receptors and their ligands. See text for further details 
Table 1 ErbB family of receptors and their ligands

\begin{tabular}{l|l}
\hline Receptor & Ligands \\
\hline EGFR & $\begin{array}{l}\text { EGF, TGF- } \alpha, \text { HBEGF (heparin-binding EGF-like growth factor), AREG } \\
\text { (amphiregulin), BTC (betacellulin), EREG (epiregulin), EPGN (epigen) }\end{array}$ \\
\hline ErbB-2 & No known ligand \\
\hline ErbB-3 & Neuregulins \\
\hline ErbB-4 & Neuregulins \\
\hline
\end{tabular}

Note that ErbB-2 has no ligand and ErbB-3 has a non-functional kinase domain, so both receptors act as subunits of other ErbBs

These transmembrane glycoproteins are composed of an extracellular ligand binding domain, a transmembrane domain and an intracellular portion, which possesses a tyrosine kinase domain. Upon ligand binding to the extracellular domain (by peptidic molecules such as epidermal growth factor (EGF) or transforming growth factor $\alpha(\mathrm{TGF}-\alpha)$, Table 1 and Fig. 1) receptor activation occurs. This process involves receptor homo-dimerisation or hetero-dimerisation with another family member. This leads to an autophosphorylation event whereby the tyrosine kinase domains of the dimer phosphorylate each other, initiating a cascade of further signaling in the cell, a process known as signal transduction. The end results of this signaling cascade can include cell proliferation and maturation, cell survival or apoptosis and in some instances angiogenesis and metastasis.

It should be noted that mutated EGF receptors with non-functional kinase domains are unable to elicit the same degree of signal transduction as the intact system, suggesting a possible role for inhibitors of the kinase domain of EGFR in prevention of EGFR mediated signal transduction.

\section{The Rationale for EGFR Inhibitors}

Clearly, the processes that follow activation of EGFR described above can be important in both tumour maintenance and progression, and intervention in these cascades by EGFR inhibition could offer therapeutic benefit. However, EGFR is expressed in both neoplastic and healthy tissue, where it has a function in maintaining skin and other internal epithelial cells, such as those of the gastrointestinal tract. A key observation though is that EGFR is highly expressed in a number of tumour types [2,4] (including NSCLC) and these high expression levels have been correlated with poor prognosis and more rapid disease progression. This body of evidence implicating over-expression of the receptor as a tumour driver has prompted a variety of approaches to target tumours using EGFR inhibitors. 


\section{The Discovery of gefitinib and erlotinib}

\section{1 gefitinib}

Early work in the field of EGFR kinase inhibitors was first disclosed by Ward et al. [5] at Zeneca Pharmaceuticals (now AstraZeneca). These workers investigated the catalytic mechanism of phosphorylation by the EGFR kinase domain in order to facilitate structure based searching for inhibitors and allow the identification of a more focused set of compounds for screening. Rate studies showed that EGFR forms a ternary complex with ATP and the peptidic substrate, and the detailed catalytic mechanism was then exploited to define a query used to interrogate a database of predicted 3D chemical structures. This involved searching for motifs that mimic that ATP $\gamma$-phosphate and the tyrosine phenol, key features of this complex catalytic system. This then enabled further 2D searching culminating in the discovery of 4-(3-chloroanilino)quinazoline (1, Fig. 2) as a potent inhibitor $\left(\mathrm{K}_{\mathrm{i}}=16 \mathrm{nM}\right)$ of the isolated enzyme.

The compound showed competitive kinetics with respect to ATP, whereas it was non-competitive with respect to the peptidic substrate, implying that it behaves as a mimic of ATP. Also noteworthy was the observation that upon limited kinase selectivity testing, 1 did not inhibit PKC (Protein Kinase C), dispelling the initial preconceptions of the time that selective kinase inhibition in this manner would not be possible. The first patent to claim anilinoquinazolines as kinase inhibitors was then filed as a result of this work [6, 7]. Interestingly, researchers at Parke-Davis were also active in the area at the same time, with their initial findings following soon after (For a refreshingly candid account of this work and the impact of the Zeneca group's and others publications on it, see [8]).

A subsequent optimisation of $\mathbf{1}[9,10]$ led to the observation $[11,12]$ that electron-donating substituents at the 6- and 7-positions of the quinazoline enhanced in vitro potency against EGFR, leading to compound 2 (Fig. 3) as a potent inhibitor of EGF-stimulated human tumour cell growth ( $\mathrm{IC}_{50} 50 \mathrm{nM} \mathrm{KB}$ oral carcinoma cells).

However, although 2 showed efficacy in a relevant in vivo tumour xenograft disease model in nude mice (A431 cell line), it was rapidly metabolised with a halflife of approximately $1 \mathrm{~h}$. Metabolite identification work (Fig. 3) revealed the presence of two major products, both resulting from oxidation. Methyl oxidation led to benzyl alcohol 3, whereas oxidation at the para-position of the aniline moiety produced the corresponding phenol metabolite 4 . Reinstalling the chloro group in place of the methyl (as in 1) and fluorination at the para position of the aniline delivered 5 (Fig. 4) which avoided the oxidation issues encountered by 2 and

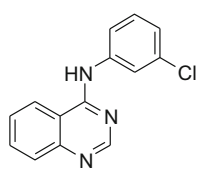

Fig. 2 Structure of 4-(3-chloroanilino)quinazoline (1) 


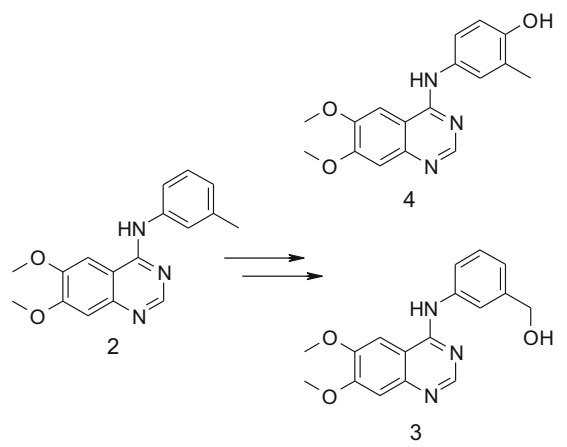

Fig. 3 Structure of $\mathbf{2}$ and in vivo $\mathbf{3}$ and $\mathbf{4}$ metabolites

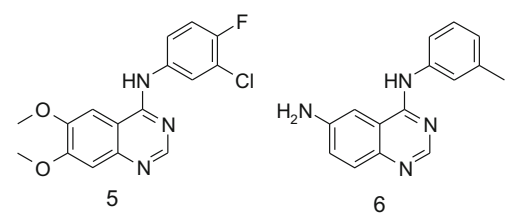

Fig. 4 Structures of 5 and 6

displayed a better in vivo profile with improved efficacy in disease models following oral dosing, accompanied by reduced plasma clearance and longer half life in mice $(3 \mathrm{~h})$. In addition, these beneficial properties were accompanied by only a slight reduction in target potency (EGFR-TK enzyme test, $\mathrm{IC}_{50} 9 \mathrm{nM}$; EGF stimulated $\mathrm{KB}$ cell growth, $\left.\mathrm{IC}_{50} 80 \mathrm{nM}\right)$. The authors also noted that whilst related compound 6 (Fig. 4) showed relatively lower potency than other analogues, it had much improved oral exposure in mice and superior in vivo efficacy, reflecting the importance of sustained inhibition of EGFR in achieving meaningful activity in this model when using a once-daily dosing regimen.

A key structural change in this regard appeared to be the substitution at the 6-position of the quinazoline and modification here formed an important part of the strategy for the remainder of the groups' efforts, employing $\mathbf{5}$ as the template for further work. The authors designs included modulation of the physicochemical properties of the template by incorporation of basic functionality into the ether side chain at the 6-position as this offered the possibility of retaining both the potency enhancing ethers at C6 and C7 and the substituted aniline at C4 which gave the optimal combination of metabolic stability and potency.

A selection of compounds prepared is shown below (Fig. 5). Using 5 as a start point, the authors prepared a series of analogues incorporating basic side chains with two or three carbon atoms between the 6-oxygen and the side-chain nitrogen atom. 

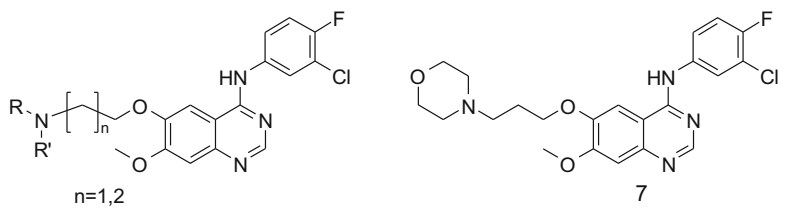

Fig. 5 Structures of optimisation targets and ZD1839 (gefitinib, Iressa ${ }^{\mathrm{TM}}$ ) 7. R, R' $=$ alkyl, cycloalkyl and heteroaromatic

From this work, compound 7 showed high potency in the EGF-stimulated cell proliferation test $\left(\mathrm{GI}_{50}=80 \mathrm{nM}\right.$ in $\mathrm{KB} 2$ cells) and excellent oral exposure in mouse and resultant high in vivo disease model efficacy and was selected as clinical candidate ZD1839. As well as having good oral bioavailability, ZD1839 inhibited the growth of a broad range of human solid tumour xenografts in a dosedependent manner with marked regressions seen in some tumours [10]. A431 xenograft tumour growth was particularly sensitive to ZD1839 treatment, with complete tumour growth inhibition observed in animals that received a once-daily oral dose of $200 \mathrm{mg} / \mathrm{kg}$. Treatment for up to 4 months in nude mice was also well tolerated and interestingly, withdrawal of drug treatment did allow some tumours to resume growth. When ZD1839 was used to treat large, well-established A431 tumours, rapid tumour regression was observed, and this was maintained for the duration of treatment. The compound was also reported to be retained in cells and consequently in vivo showed some characteristics of an irreversible inhibitor [13]. ZD1839 was assigned the international nonproprietary name gefitinib and the brand name Iressa ${ }^{\mathrm{TM}}$, and demonstrated a long half-life in humans (approximately 48 h) compatible with once-daily oral dosing. Extensive Phase I clinical trials also showed biomarker evidence for inhibition of the EGFR signal transduction pathway and antitumour activity [14-16]. The maximum tolerated dose in patients was $800 \mathrm{mg}$, with dose limiting toxicities of diarrhea and skin rash being observed. Pharmacokinetic analysis of patient samples showed that doses of $150 \mathrm{mg} / \mathrm{day}$ and above led to plasma concentrations of $>200 \mathrm{nM}$ and drove responses in around a third of patients treated, with tumour responses not limited to NSCLC but ranging from ovarian and prostate to colorectal and head and neck.

\section{2 erlotinib}

Erlotinib hydrochloride (8, Fig. 6) was originally discovered as an EGFR kinase inhibitor by researchers working at Pfizer [17]. Subsequent development was to be conducted in collaboration with OSI (Oncogene Science Inc.), however the 2000 merger between Pfizer and Warner-Lambert meant that Pfizer were obliged to grant all development and marketing rights for the compound to OSI pharmaceuticals and was given the international nonproprietary name erlotinib. Under the brand name of 


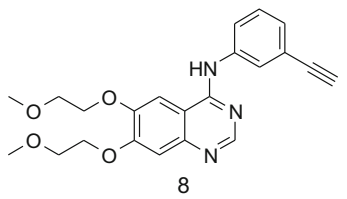

Fig. 6 Structure of OSI-774 (erlotinib, Tarceva ${ }^{\mathrm{TM}}$ ) 8

$\operatorname{Tarceva}^{\mathrm{TM}}$, the compound is currently marketed by OSI in collaboration with Roche/Genentech.

Although a good deal of data have been published around erlotinib [18, 19], to date the medicinal chemistry story does not appear to have been disclosed. Nevertheless, the SAR that was exploited in the discovery of gefitinib and related anilinoquinazoline EGFR inhibitors is visible in the erlotinib structure. A lipophilic substituent at the meta position of the aniline (in this case an alkyne), combined with C6, C7 ether substituents drives high potency. Interestingly, the symmetrical C6, C7 ether substitution pattern of erlotinib imparts good physicochemical properties relative to other substitution patterns, and higher blood levels in pre-clinical species than gefitinib. The compound is reported to be less potent than gefitinib in many in vivo models, but an oral dose of $50 \mathrm{mg} /$ day provides sufficient exposure (plasma concentration $>1.25 \mu \mathrm{M}$ ) for efficacy [20]. In the case of erlotinib, the maximum tolerated dose is $200 \mathrm{mg} /$ day and, as for gefitinib, the dose limiting toxicities observed are diarrhea and skin rash [21]. The binding modes of gefitinib and erlotinib in the EGFR kinase domain are illustrated by the X-ray structures shown in Fig. 7. The quinazoline templates are oriented in a very similar fashion, with the quinazoline $\mathrm{N} 1$ accepting a hydrogen bond from the backbone $\mathrm{NH}$ of methionine 793 in the hinge region of the kinase. The hinge region (the segment that connects the amino- and carboxy-terminal lobes of the kinase domain, so called because it moves to enclose itself around ATP when it binds like a hinge) contains several conserved residues that provide the catalytic machinery and makes up an essential part of the ATP binding pocket. The aniline rings are also positioned in a similar way in the protein, with the lipophilic meta-group also occupying the same space. Finally, the ether linked groups in both examples are directed towards the solvent channel.

Iressa $^{\mathrm{TM}}$ was first approved by the United States FDA on the 5th of May 2003 on the basis of Phase II data and under accelerated approval as "monotherapy for the treatment of patients with locally advanced or metastatic non-small cell lung cancer after failure of both platinum based and docetaxel chemotherapies" employing a $250 \mathrm{mg}$ once-daily oral dose. However, this initial registration was based on objective response rates and subsequent studies did not show an increase in overall survival. The median survival in the "ISEL" trial for gefitinib patients was 6.3 months, versus 5.4 months for placebo, just short of statistical significance. Consequently, in June 2005, the product was withdrawn and only supplied to patients who had previously shown benefit from Iressa ${ }^{\mathrm{TM}}$ treatment. Tarceva $^{\mathrm{TM}}$ received its first approval as a $100 \mathrm{mg}$ dose of the hydrochloride salt from the FDA 

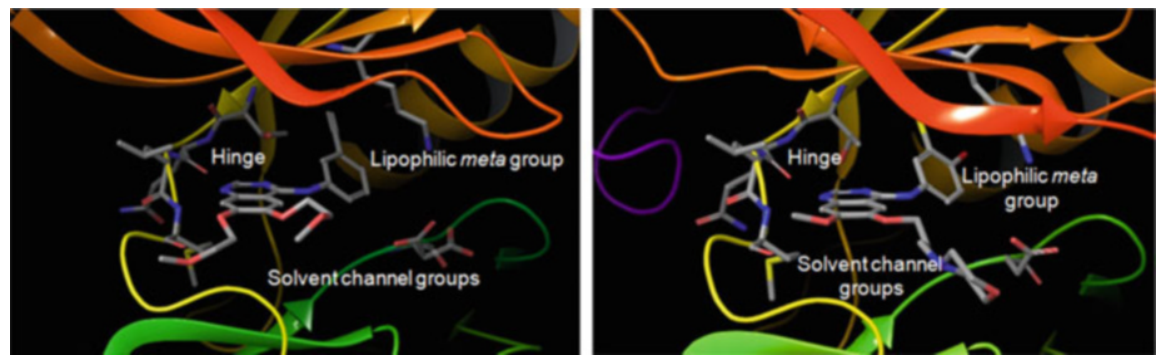

Fig. 7 X-ray structures of erlotinib (A, 1M17) and gefitinib (B, 2ITZ) bound to EGFR kinase domain

on the 19th of November 2004, and did demonstrate a slight but statistically significant increase in overall survival of 6.7 months versus 4.7 months in the placebo control group. Some consideration should be given to the possible reasons behind the contrasting outcomes of the pivotal studies for these two similar compounds. Certainly the patient populations studied were different, with gefitinib being dosed in a high proportion of Eastern European trial centres, with more heavy smokers and possibly more seriously ill patients. Gefitinib was also not studied at its maximum tolerated dose which may also have had an influence on the trial outcome. However, sub-population analysis of all trial data showed Asian, female, non-smokers (a segment that frequently carries EGFR sensitising mutations, vide infra) benefited significantly from Iressa ${ }^{\mathrm{TM}}$, and marketing approval was confirmed in Japan and the Far-East. After these initially disappointing clinical results with gefitinib and erlotinib in broad NSCLC patient populations, these compounds have subsequently shown clinical efficacy in NSCLC patients with activating mutations of EGFR.

\section{Quinazoline-Based Irreversible EGFR Kinase Inhibitors}

Over the past decade and a half, a number of groups have disclosed their efforts towards the identification of anilinoquinazoline-based irreversible EGFR kinase inhibitors that form a covalent bond with C797 in the ATP binding site of the kinase. Covalent inhibitors offer a number of advantages over their reversible counterparts, including extended pharmacodynamic activity (often lasting well beyond the detectable systemic presence of the inhibitor) as well as opportunities for exceptionally high target potency due to no-longer having to compete with high cellular ATP concentrations [8, 22, 23]. Nevertheless, the clear advantages with this approach do need to be weighed in the presence of potential risks, and in particular the possibility of idiosyncratic toxicology of compounds due to haptenisation. This can occur when the reactive warhead of the covalent inhibitor reacts with protein nucleophilic residues other than that which it was designed to target. The modified 


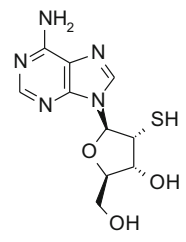

Fig. 8 Structure of $2^{\prime}$-thioadenosine 9

protein can then be recognised by the immune system as being "non-native" and the accompanying immunological response can be severe. Consequently, it is important that the affinity of the ligand for the target protein $\left(\mathrm{K}_{\mathrm{i}}\right)$ should be as high as possible, thus allowing the reactivity of the warhead $\left(\mathrm{k}_{\text {inact }}\right)$ to be relatively modest and less likely to indiscriminately react with available nucleophilic residues.

Whilst some early mechanistic studies in the area of covalent EGFR inhibitors were reported by Clark [24] and Woltjer [25], the first structure based design of an irreversible Erb family kinase domain inhibitor was reported by Singh et al. [26] who examined the nucleotide binding site of EGFR for possible positions for the attachment of a covalent inhibitor. C797 in the ATP binding site was postulated as a potential target due to its relative ease of access, and the residue's ability to form a covalent bond to an inhibitor was tested by incubation with $2^{\prime}$-thioadenosine (9, Fig. 8).

This agent was able to covalently inactivate EGFR and the inhibition was reversed by $1 \mathrm{mM}$ dithiothreitol, implying that this inhibition is occurring through covalent modification of C797 by formation of a disulfide bond. Interestingly, kinetic data showed that inhibition occurred through formation of a non-covalent complex followed by slow formation of the disulfide bond. Selectivity was also achieved over FGF, PDGF or insulin receptor tyrosine kinases which were not inhibited by $2^{\prime}$-thioadenosine.

\section{1 canertinib}

Building on this work, joint studies by workers at Auckland University and ParkeDavis [27] employed an anilinoquinazoline as their template to examine covalent EGFR inhibitors. Rather than relying on disulfide bond formation, these workers instead studied an electrophilic acrylamide warhead on the template (Fig. 9). Guided by molecular modelling, the $\mathrm{C} 6$ position of the quinazoline template was viewed as being suitably close in space to C797 to allow covalent modification and this did prove to be the case in practice with the $\mathrm{C} 7$ analogue $\mathbf{1 2}$ reacting with $\mathrm{C} 797$ at a much slower rate than 10. An X-ray structure of the simple quinazoline analogue 13 bound to the EGFR kinase domain (generated after this work by a different group) illustrates this point (Fig. 10). Additional work showed that the alkylation reaction occurs with a 1:1 stoichiometry. The compounds were also stable in solution and only undergo reaction when bound to the protein. A final 

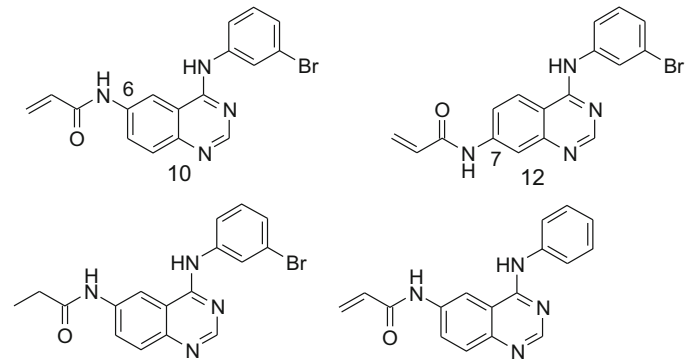

11

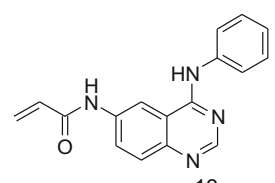

13

Fig. 9 Early anilinoquinazoline based EGFR irreversible inhibitors and reversible comparator

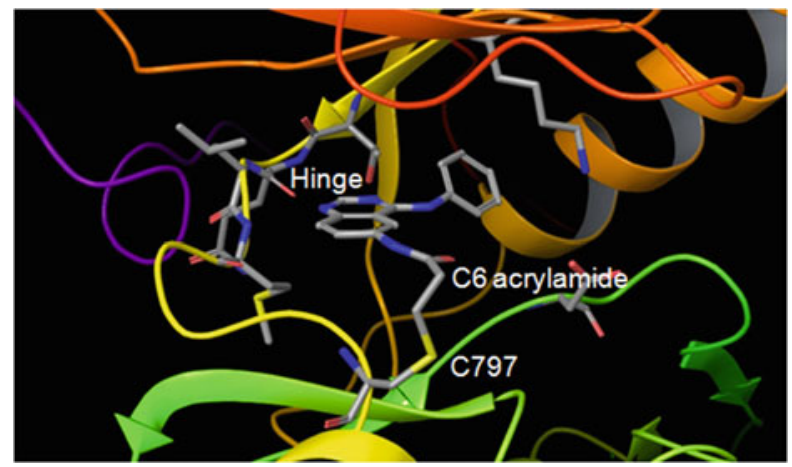

Fig. 10 X-ray structures of quinazoline 13 (2J5E) bound to EGFR kinase domain

outcome from this work was that a comparison between 6-acrylamido-4anilinoquinazoline $\mathbf{1 0}$ and an equally potent but reversible analogue $\mathbf{1 1}$ showed that the irreversible inhibitor had far superior in vivo efficacy in a human epidermoid carcinoma xenograft model.

In a report of further efforts on these scaffolds by these groups [28], the cell potency of pairs of compounds bearing C6 or C7 acrylamides was examined (Table 2). As before, the C6 position delivered higher potency than C7 substitution, and this was particularly evident in a cellular autophosphorylation assay (compare 14 and 15).

Modifications to the central core of the parent quinazoline motif were also investigated. Three new cores were prepared, and representative examples 16, 17 and $\mathbf{1 8}$ are shown in Table 3. In the case of the examples bearing the acrylamide at the 7-position (e.g. 17), aza substitution led to a loss of cell potency, reinforcing the view that this position is not optimal for acrylamide attachment, especially when considering that the heteroatom introduction should make the warhead more reactive.

The remainder of the examples studied in these new cores were all 6-substituted and in general tolerated the structural changes made. Of note though is the observation that the two heterocyclic analogues $\mathbf{1 6}$ and $\mathbf{1 8}$ were less potent than expected 
Table 2 Comparison of EGFR potencies of C6 and C7 acrylamide isomers

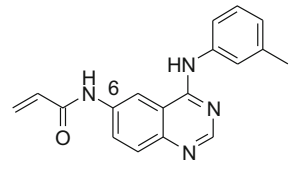

14

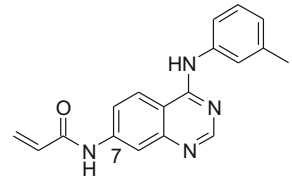

15

\begin{tabular}{l|l|l}
\hline Compound & $\mathbf{1 4}$ & $\mathbf{1 5}$ \\
\hline EGFR isolated enzyme $\mathrm{IC}_{50 \mathrm{app}}(\mathrm{nM})$ & 0.42 & 1.6 \\
\hline EGFR cell autophosphorylation $(\mathrm{A} 431) \mathrm{IC}_{50 \mathrm{app}}(\mathrm{nM})$ & 4.7 & 90 \\
\hline
\end{tabular}

Table 3 Comparison of EGFR potencies of heterocyclic C6 and C7 acrylamide isomers<smiles>C=CC(=O)Nc1ccc2ncnc(Nc3ccc(F)c(Cl)c3)c2n1</smiles>

16<smiles>C=CC(=O)Nc1cc2ncnc(Nc3cccc(Br)c3)c2cn1</smiles><smiles>C=CC(=O)Nc1cc2c(Nc3ccc(F)c(Cl)c3)ncnc2cn1</smiles>

18

\begin{tabular}{l|l|l|l}
\hline Compound & $\mathbf{1 6}$ & $\mathbf{1 7}$ & $\mathbf{1 8}$ \\
\hline EGFR isolated enzyme $\mathrm{IC}_{50 a p p}(\mathrm{nM})$ & 0.75 & 0.54 & 0.77 \\
\hline EGFR cell autophosphorylation $(\mathrm{A} 431) \mathrm{IC}_{50 a p p}(\mathrm{nM})$ & 18 & 108 & 3.3 \\
\hline ErbB2 cell autophosphorylation $(\mathrm{MDA}-\mathrm{MB}-453) \mathrm{IC}_{50 \mathrm{app}}(\mathrm{nM})$ & 12 & & 3.0 \\
\hline
\end{tabular}

in the cell assay, and the authors speculate that this could be attributable to increased electrophilicity associated with the more electron deficient acrylamide leading to non-specific alkylation and consequently loss of active inhibitor. Alternatively the authors also suggest that the aniline may adopt a different conformation in the presence of the 5-aza atom. It was also observed that pyridopyrimidines were now equipotent against EGFR and ErbB2 in the cell based assays employed. Finally, the effect of different substitution patterns in the aniline ring of the anilinoquinazoline template was examined. These compounds largely recapitulated earlier observations described above that a lipophilic aniline meta substituent seemed most favourable for potency and that a metabolic blocking group at the para-position tended to reduce clearance and prolong in vivo half lives. Compounds with large, sterically demanding groups at the para-position were generally not beneficial for potency.

Six compounds from this work (including 18) were all active in vivo when dosed either orally or via the IP route in A431 or H125 tumour xenograft models (both EGFR wild-type), but it was not possible to discern major efficacy differences between the compounds, although it did become clear that IP dosing caused greater 
tolerability issues than the oral route. Although cytostatic activity was evident for these compounds, aqueous solubility was also reported to be challenging, and as a consequence the compounds were dosed as fine particulate emulsions. Solubility could be altered slightly by modification of the aniline substituent (in the order $3^{\prime}-\mathrm{Br}<3^{\prime}-\mathrm{Cl}<3^{\prime}-\mathrm{CF}_{3}<3^{\prime}-\mathrm{CH}_{3}$ ), but it was apparent that further improvement would be required before this chemotype could be progressed towards a clinical candidate.

Initial efforts to improve aqueous solubility were focussed on the introduction of cationic solubilising groups at the $4^{\prime}$ position [29]. As has been described above, introduction of groups here previously led to a slight reduction in potency compared to the unelaborated systems, and so the authors elected to also incorporate a meta bromo substituent, known to enhance EGFR potency, compound 19, Table 4.

Unfortunately, whilst these compounds did show improved solubility relative to parent, they suffered a large loss of potency against EGFR as well as no longer displaying a covalent mode of inhibition. A more fruitful avenue for exploration was the 7-position of the quinazoline. Previous work had shown that ether linkers at this position improved EGFR potency, and in addition modelling work and earlier SAR had established that solubilising side chains were tolerated at this location [11, 12]. Fixing the aniline meta group initially as a bromine and incorporating a variety of bases with differing $\mathrm{pK}_{\mathrm{a}} \mathrm{s}$ and two or three carbon chain linkers proved successful in delivering soluble, potent irreversible EGFR inhibitors. In contrast, an S-linked basic example was much less potent. The C7 methylpiperazinepropoxy and morpholinopropoxy ether derivatives were also combined with the 3-Me aniline head group, although these analogues did show reduced potency in the cell assay. Finally, two $4^{\prime}-\mathrm{F}$ analogues (to reduce clearance and extend in vivo half life, vide supra) were combined with the morpholinylpropoxy sidechain and $3^{\prime} \mathrm{Br}$ and $3^{\prime} \mathrm{Cl}$ potency enhancing groups to provide compounds $\mathbf{2 0}$ and $\mathbf{2 1}$ (Table 5) with comparable potency to the non-solubilised or fluorinated versions, showing that the positive benefits of improved solubility and reduced clearance can be achieved without compromising potency.

As has been described above, the authors had previously examined the introduction of additional heteroatoms to the anilinoquinazoline core, and it was postulated that this might also benefit the solubility of this system by reducing

Table 4 Structure of analogues $\mathbf{1 0}$ and $\mathbf{1 9}$

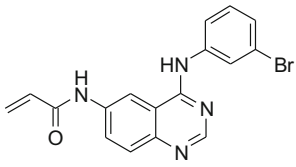

10

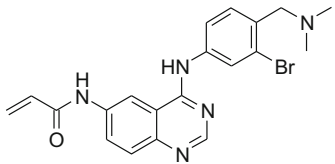

19

\begin{tabular}{l|l|c}
\hline Compound & $\mathbf{1 0}$ & $\mathbf{1 9}$ \\
\hline EGFR isolated enzyme $\mathrm{IC}_{50 \mathrm{app}}(\mathrm{nM})$ & 0.7 & 45 \\
\hline EGFR cell autophosphorylation $(\mathrm{A} 431) \mathrm{IC}_{50 \mathrm{app}}(\mathrm{nM})$ & 2.7 & 416 \\
\hline
\end{tabular}


Table 5 Structure of analogues 20 and 21 (canertinib, CI-1033, PD-0183805, Parke-Davis/ University of Auckland)
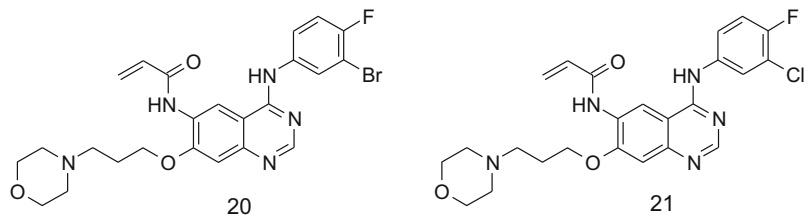

\begin{tabular}{l|l|l}
\hline Compound & $\mathbf{2 0}$ & $\mathbf{2 1}$ \\
\hline EGFR isolated enzyme $\mathrm{IC}_{50 \text { app }}(\mathrm{nM})$ & 1.8 & 1.5 \\
\hline EGFR cell autophosphorylation $(\mathrm{A} 431) \mathrm{IC}_{50 a p p}(\mathrm{nM})$ & 4.7 & 7.4 \\
\hline
\end{tabular}

Table 6 Structure of analogues 22, 23 and 24
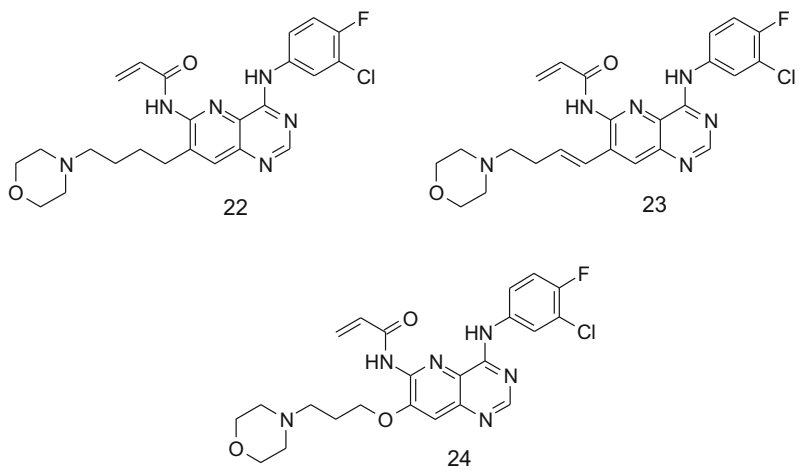

\begin{tabular}{l|l|l|l}
\hline Compound & $\mathbf{2 2}$ & $\mathbf{2 3}$ & $\mathbf{2 4}$ \\
\hline EGFR isolated enzyme $\mathrm{IC}_{50 \text { app }}(\mathrm{nM})$ & 2.7 & 0.16 & 1.5 \\
\hline EGFR cell autophosphorylation $(\mathrm{A} 431) \mathrm{IC}_{50 \mathrm{app}}(\mathrm{nM})$ & 5,100 & 119 & 434 \\
\hline ErbB2 cell autophosphorylation $(\mathrm{MDA}-\mathrm{MB}-453) \mathrm{IC}_{50 \text { app }}(\mathrm{nM})$ & $>5,000$ & 12 & 189 \\
\hline
\end{tabular}

lipophilicity. Consequently, a number of pyrido[3,2- $d]$-pyrimidines bearing cationic side chains at $\mathrm{C} 7$ were prepared (Table 6).

Analogue 22, in which the basic sidechain was attached via a carbon as opposed to the more usual oxygen linker showed good activity in the EGFR biochemical assay but much reduced activity in the cellular autophosphorylation setting. In a similar vein, unsaturated analogue $\mathbf{2 3}$ again was a potent enzyme inhibitor but once more showed a large drop off when moving to the cell assay. The remaining examples prepared in this core were characterised by basic side chains appended to the pyrido[3,2- $d]$-pyrimidine core with the more usual ether linker. As described in their previous work, the authors once again noted that whilst these compounds were potent biochemical EGFR inhibitors, upon moving to the cell assay, their activities were, on the whole, disappointing. A number of studies were performed to further investigate this disconnect. By using mass spectrometry, it was shown that 
22 formed a 1:1 adduct with the EGFR protein (some 1:2 protein:drug adduct was also observed). By using trypsin digestion of the drug-bound protein and analyses by LC-ESI tandem mass spectrometry (MS/MS) it was shown that C797 was the residue being alkylated. Examination of the permeability and efflux profile of $\mathbf{2 4}$ using a $\mathrm{CACO} 2$ assay demonstrated that the compounds were permeable with low efflux potential. Following examination of relative warhead stability using a glutathione conjugation assay, it was eventually concluded that, as initially proposed before in their earlier work, the introduction of the heteroatom renders the acrylamide in $\mathbf{2 2}$ too reactive to and it is therefore not sufficiently long-lived in a cellular environment to bind appreciably to EGFR.

With a selection of potent inhibitors available, the in vivo efficacy of three compounds in a tumour xenograft model (A431 cell line) was then examined. Compound 21 (Table 5) was well tolerated and showed excellent activity at an oral dose of $5 \mathrm{mg} / \mathrm{kg}$ for 14 days. This compound (as the dihydrochloride salt) was subsequently selected as a clinical candidate for further investigation, receiving the identifier CI-1033 and subsequently being known as canertinib. The structural similarities between canertinib and gefitinib can be seen, both contain an identical anilinoquinazoline core with the only differences between the compounds being migration of the basic side chain from $\mathrm{C} 6$ to $\mathrm{C} 7$ and the incorporation of the acrylamide functionality at $\mathrm{C} 6$.

Initial Phase I clinical testing of canertinib was conducted in NSCLC patients, but was discontinued due to skin toxicity. Subsequent trials in metastatic breast cancer appeared more favourable, with the compound advancing as far as Phase II trials. However, its development has been discontinued due to the observation of thrombocytopenia.

\section{2 pelitinib}

Almost simultaneously with the studies that delivered canertinib, researchers at Wyeth-Ayerst had also been exploring a similar quinazoline-based approach to covalent EGFR inhibitors. Following their initial disclosures [30], this group subsequently described their work around the quinazoline acetylene derivative $\mathbf{2 5}$ [31], before finally settling on the clinical candidate EKB-569 (26, Fig. 11) now known as pelitinib [32]. During the course of this work, the group performed insightful studies on the relative reactivity of butynamide, crotonamide and methacrylamide cysteine targeting warheads. Of particular note was the observation that incorporating a dialkylamino group onto the acrylamide $\beta$-position gave compounds with greater cysteine reactivity, postulated to be due to the basic group mediating intramolecular proton transfer during the Michael addition. The presence of the base also imparted generally improved physicochemical properties to the compounds due to lowered lipophilicity. As for canertinib, the architectural similarity with gefitinib is evident, although in this case, the hinge binding template is cyanoquinoline rather than quinazoline based. Despite entering the clinic and 
Fig. 11 Structures of Wyeth-Ayerst quinazoline 25, pelitinib (EKB-569, Wyeth-Ayerst) 26, dacomitinib (PF-00299804, Pfizer) 27 and afatinib (Gilotrif $^{\mathrm{TM}}$, Tovok ${ }^{\mathrm{TM}}$, BIBW-2992, Boerhinger Ingelheim), 28

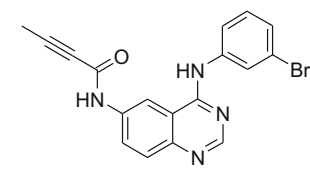

25

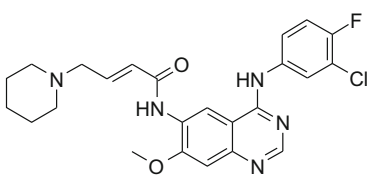

27

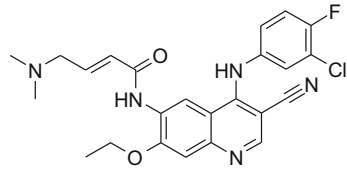

26

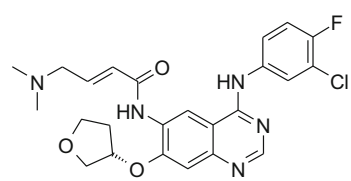

28

proceeding to phase II testing in both NSCLC and colorectal cancer, no further updates have been reported and the compound is believed to have been discontinued.

\section{3 dacomitinib}

The medicinal chemistry program leading to the discovery of dacomitinib (PF-00299804, 27, Fig. 11) has not been disclosed. The compound is described as an oral, once-daily, pan-HER inhibitor. It is an irreversible inhibitor of HER-1 (EGFR), HER-2 and HER-4 tyrosine kinases, and is structurally related to canertinib (21) and pelitinib (26). The main differences between canertinib and dacomitinib are the migration of the base at $\mathrm{C} 7$ in the former to the acrylamide functionality at $\mathrm{C} 6$ of the latter, a feature also seen originally in pelitinib.

Nevertheless, it has been reported [33] that dacomitinib possesses greater oral bioavailability, longer half-life, larger volume of distribution and lower plasma clearance than canertinib. Clinical investigation of this agent is ongoing [34], although progress in its use in the treatment of recurrent and/or metastatic head and neck squamous cell cancer has not been updated for some time. Dacomitinib was also studied in the treatment of patients with locally advanced or metastatic NSCLC. Unfortunately, in January 2014 it was announced that in this setting, neither progression free survival relative to erlotinib nor overall survival compared with placebo was improved. A further trial comparing dacomitinib to gefitinib in treatment naïve advanced NSCLC patients remains ongoing at the time of writing. Most recently, in 2015, the compound received orphan drug status designation for the treatment of non-small cell lung cancer with EGFR, HER2, HER4, or DDR2 mutations. 


\section{4 afatinib}

Afatinib (BIBW2992) (28, Fig. 11) is another anilinoquinazoline-based irreversible EGFR inhibitor and was discovered by researchers at Boerhinger Ingelheim [35].

Again, little has been published around the medicinal chemistry program that led to the identification of this agent. It has been noted that the potent HER2 activity of afatinib, in addition to its EGFR potency, may offer additional indications relative to earlier inhibitors [36]. Afatinib and dacomitinib are structurally similar, with afatinib employing a dimethylamine rather than piperidine as the base appended to the acrylamide. In addition, afatinib also now contains a $3 S$-tetrahydrofuarn-3-yloxy group at C7. To date, afatinib is the only irreversible anilinoquinazoline-based EGFR inhibitor approved by the FDA and it was launched in the USA as Gilotrif ${ }^{\mathrm{TM}}$ in July 2013. Currently it is approved for first-line treatment for patients with metastatic NSCLC who carry an activating EGFR mutation (see below) with a recommended daily dose of $40 \mathrm{mg}$. The drug was also launched for this indication in the UK and Japan in 2014. Afatinib is also in Phase III clinical trials for a variety of other tumour types including metastatic breast cancer, as well as recurrent and/or metastatic head and neck squamous cell carcinoma.

\section{EGFR Mutant Selective Inhibitors}

\subsection{Sensitising/Activating Mutations}

The clinical development of both gefitinib (7) and erlotinib (8) was complicated by a lack of knowledge of the genetic backgrounds of the patients recruited into the trials and an understanding of how that genetic profile might impact their response to treatment. Following Phase I trials, broad, non-selected NSCLC patient populations were targeted in subsequent studies and disappointing results were observed for these compounds, although, as described above, the erlotinib data was sufficient to allow approval. Subsequent analysis of the data revealed possible reasons for these outcomes. The intended target for these EGFR inhibitors was the wild-type form of the receptor, but retrospective examination of the tumours of those patients that responded to gefitinib and erlotinib showed an unexpected finding [37]. A common characteristic of the responding patients was the presence of mutations in the kinase domain of the receptor. The mutations identified (Fig. 12) were either the single point mutation of L858R or Exon19 deletion (deletion of the amino acid sequence 746-750 from the protein chain).

These changes were found to render the receptor constitutively activated, independent of ligand stimulation [39]. In addition, further examination of these mutants also showed that they caused a reduced affinity of the kinase for ATP [40], thus rendering the receptors more susceptible to inhibition by an ATP competitive inhibitor (Table 7). Consequently, these mutations were termed activating, or sensitising, mutations of EGFR. Those patients carrying these mutations were 


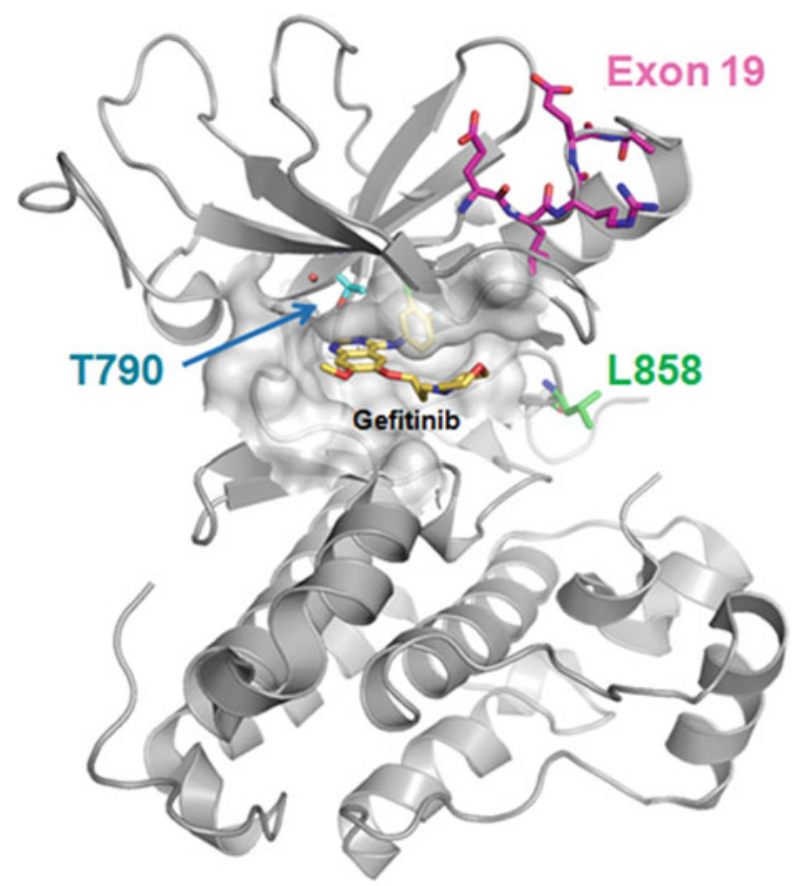

Fig. 12 Crystal structure of EGFR kinase domain, highlighting location of activating (Exon19 deletion and L858R) and resistance (T790M) mutations. Reprinted (adapted) with permission from Ward et al. [38]. Copyright (2013) American Chemical Society

Table 7 Cell data for gefitinib and erlotinib

\begin{tabular}{l|l|l|l}
\hline $\begin{array}{l}\text { Compound } \\
\text { number }\end{array}$ & $\begin{array}{l}\mathrm{PC} 9 \mathrm{p}-\mathrm{EGFR} \\
\mathrm{EC}_{50}(\mu \mathrm{M})\end{array}$ & $\begin{array}{l}\text { LoVo p-EGFR } \\
\mathrm{EC}_{50}(\mu \mathrm{M})\end{array}$ & $\begin{array}{l}\mathrm{H} 1975 \text { p-EGFR } \\
\mathrm{EC}_{50}(\mu \mathrm{M})\end{array}$ \\
\hline $\mathbf{7}$ (gefitinib) & 0.007 & 0.059 & 3.1 \\
\hline $\mathbf{8}$ (erlotinib) & 0.006 & 0.084 & 6.1 \\
\hline
\end{tabular}

PC9 cells (exon19 deletion EGFR), LoVo cells (wild-type EGFR), H1975 cells (L858R/T790M EGFR)

observed to be those who responded more favourably to gefitinib or erlotinib. As a result of the growing understanding of which patients would respond to gefitinib treatment, Iressa ${ }^{\mathrm{TM}}$ was approved for first-line treatment of patients with advanced EGFR mutation-positive NSCLC by the European Medicines Agency in June 2009 and subsequently by the FDA in July 2015. In addition, both erlotinib and afatinib have also been granted approval in this setting based on these findings. Further understanding has also emerged over the biological role of the wild-type form of the EGF receptor. As was noted above, EGFR has an important function in the maintenance of epithelial tissues such as the skin and the lining of the digestive tract, and its inhibition is believed to lead to the dose limiting toxicities of skin rash 
and diarrhea [41] that are observed in the clinic with gefitinib, erlotinib and afatinib. Key to the successful utilisation of erlotinib and gefitinib in the clinic has been the fortuitous difference in ATP affinity between wild-type EGFR and the sensitising mutations. As the latter forms have lower affinity for ATP than wild-type (and consequently are easier to inhibit), then it is possible to have a degree of selectivity for the mutants over the wild type (see Table 7), allowing disease efficacy before the onset of toxicity, although this will still limit the achievable dose.

\subsection{Resistance Mutations}

Around $70 \%$ of patients carrying a sensitising mutation respond to treatment with EGFR inhibitors, but most patients develop resistance to these therapies after an average of 10-11 months. In around two thirds of these cases, resistance and subsequent disease progression is due to the acquisition of a second mutation in the EGFR kinase domain, in addition to the sensitising mutation [42]. This "double mutant" now possesses a methionine residue in place of the natural threonine at position 790 (the so-called gatekeeper residue as it controls ease of inhibitor access to the so-called back pocket, Fig. 12). As in the case of the sensitising mutation, the presence of the double mutant impacts several key aspects of the kinase function, and these can help rationalise why the double mutant leads to resistance. It has been shown that, in contrast to the sensitising mutations that reduce the ATP affinity of the kinase, the double mutant has a similar ATP to that of the wild-type and consequently diminishes the ability of an ATP competitive inhibitor to impede double mutant kinase function whilst maintaining a margin to wild-type (Table 7) $[40,43]$. The change from a threonine to methionine gatekeeper also reduces the ability of anilinoquinazolines to bind to the T790M mutant form, due to the increased steric demands of the methionine residue, which is postulated to interact less favourably with the aniline portion. Given the above findings, it was hypothesised that irreversible EGFR inhibitors such as afatinib described above might offer a way to circumvent the high ATP affinity of the double mutant system, and in vitro this was shown to be the case [44]. However, the C797 residue that these inhibitors covalently bind to is conserved across not just the sensitising and T790M mutants but also in the wild-type form of the kinase. As such afatinib, canertinib and dacomitinib exhibit potency against the mutated receptor forms, but they also display potent wild-type inhibition to the extent that the toxicity from the latter prevents dosing these agents at a sufficient level to meaningfully inhibit the double mutant in a clinical setting. In light of the clinical challenges posed by the double mutant, a number of groups attempted to design "mutant selective" inhibitors that preferentially inhibit both sensitising and resistance mutations while sparing the wild-type form of the receptor. Such an agent would potentially lead to a therapy that would overcome the T790M resistance issue whilst also delivering a more benign tolerability profile due to reduced wild-type activity. 
Researchers from the Dana-Farber Cancer Institute (DFCI) were the first group to disclose their efforts towards EGFR inhibitors with a T790M "mutant selective" profile [45]. This group prepared a library of common kinase inhibitor core scaffolds in which one of the sidechains was modified by incorporation of an acrylamide motif, placed in such a way as predicted by molecular modeling to interact covalently with C797 as described above. The library was then screened in cells expressing both the sensitising and resistance EGFR mutations. Three closely related pyrimidines (29, 30 and 31, Fig. 13) identified from this work showed high potency against the L858R/T790M mutant EGFR cells (H1975) with selectivity over the wild-type expressing cell line HN11.

Further work also showed that the compounds formed a 1:1 adduct with the protein, and mass spectrometry analysis of a pepsin digest of the modified protein showed C797 as the site of modification. An X-ray crystal structure of compound 30 bound to EGFR T790M kinase domain explained several aspects of their potency and wild-type selectivity observations (Fig. 14).

Key findings were the interaction of the pyrimidine 5-chloro group with the methionine gatekeeper, with the authors postulating that this lipophilic interaction drove the observed double mutant potency and increased wild-type selectivity.

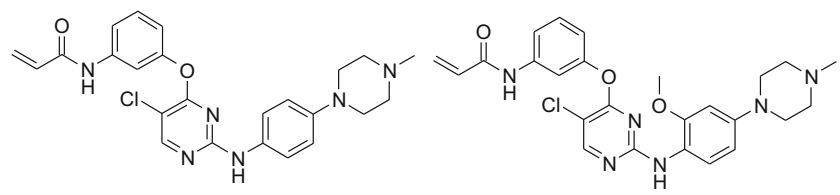

29

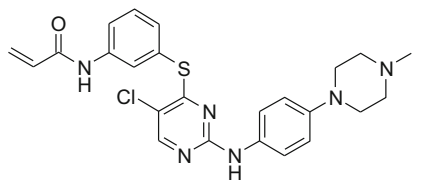

31

Fig. 13 Structures of Dana Farber EGFR hits (29), (30) and (31)

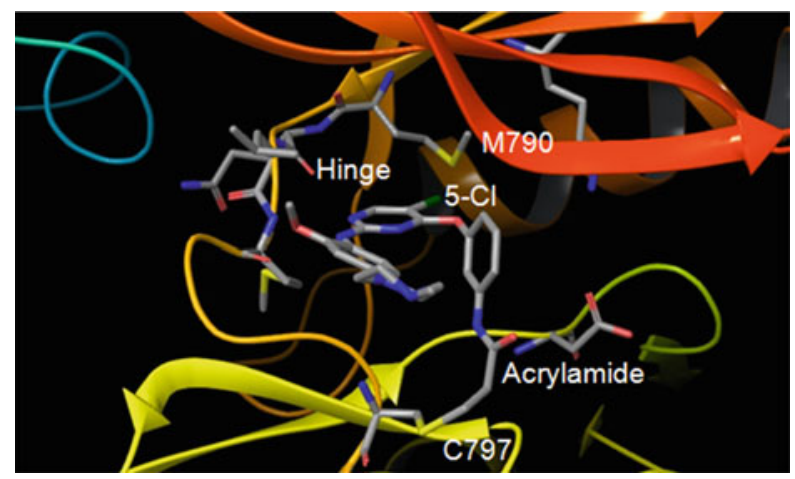

Fig. 14 X-ray structure of 30 (3IKA) bound to EGFR kinase domain 
In addition the X-ray structure confirmed the formation of a covalent bond between C797 and the acrylamide group and the role of the anilinopyrimidine group in providing a hydrogen bond donor and acceptor motif with the kinase "hinge". 30 was then selected for in vivo profiling, largely based on its primary potency for the double mutant along with low wild-type EGFR potency and lack of activity against other cysteine containing kinases. Pharmacokinetic evaluation revealed an oral half-life of $2.5 \mathrm{~h}$ and a bioavailability of $24 \%$. Mouse pharmacodynamic studies demonstrated significant knock down of both phospho-EGFR and downstream markers such as AKT and ERK1/2. Additionally, the compound showed good efficacy in anti-tumour studies against T790M xenografts, with tumour regressions being evident following 14 days oral dosing. Finally, in vitro the authors were able to demonstrate that treating cells harbouring sensitising mutations with $\mathbf{3 0}$ did not lead to the emergence of the T790M mutation, in contrast to gefitinib treatment. No further development $\mathbf{3 0}$ has been disclosed.

An initial disclosure from Celgene Avilomics Research (originally Avila Therapeutics) described the discovery of the covalent inhibitor 32 (Table 8) [46].

Table 8 Structures and selected cell data for Celgene compounds 32, 33, 34, 35, 36 and 37<smiles>C=CC(=O)Nc1cccc(Nc2cc(Nc3cccc(Br)c3)ncn2)c1</smiles>

32<smiles>C=CC(=O)Nc1cccc(Nc2nc(Nc3ccc(N4CCOCC4)cc3OC)ncc2C(F)(F)F)c1</smiles>

34

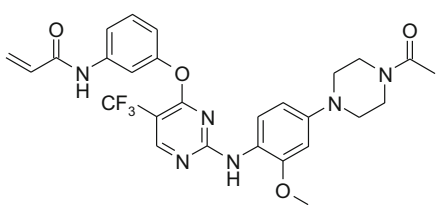

36<smiles>C=CC(=O)Nc1cccc(Nc2nc(Nc3ccccc3)ncc2C)c1</smiles>

33

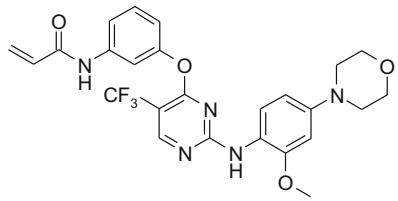

35

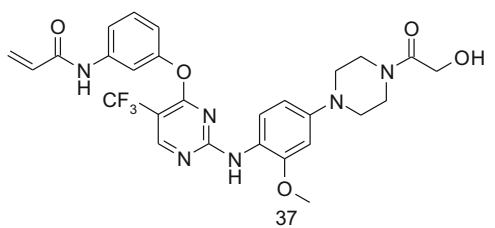

\begin{tabular}{l|l|l|l|l}
\hline $\begin{array}{l}\text { Compound } \\
\text { number }\end{array}$ & $\begin{array}{l}\mathrm{A} 431 \mathrm{p}-\mathrm{EGFR} \\
\mathrm{EC}_{50}(\mathrm{nM})\end{array}$ & $\begin{array}{l}\mathrm{H} 1975 \mathrm{p}-\mathrm{EGFR} \\
\mathrm{EC}_{50}(\mathrm{nM})\end{array}$ & $\begin{array}{l}\mathrm{A} 431 \text { proliferation } \\
\mathrm{GI}_{50}(\mathrm{nM})\end{array}$ & $\begin{array}{l}\mathrm{H} 1975 \\
\text { proliferation } \\
\mathrm{GI}_{50}(\mathrm{nM})\end{array}$ \\
\hline $\mathbf{3 4}$ & 3,304 & 48 & 1,305 & 130 \\
\hline $\mathbf{3 5}$ & 2,529 & 35 & 1,416 & 132 \\
\hline $\mathbf{3 6}$ & $>4,331$ & 58 & 602 & 48 \\
\hline $\mathbf{3 7}$ & 1,669 & 75 & 727 & 50 \\
\hline
\end{tabular}

A431 cells (wild-type EGFR), H1975 cells (L858R/T790M EGFR) 
Whilst 32 was shown to bind to $\mathrm{C} 797$ and displayed impressive activity against the sensitising and T790M double mutant in both cellular EGFR phosphorylation and proliferation assays, this was also accompanied by very high levels of wild-type activity. Modifying the pyrimidine substitution pattern and incorporation of a methyl group at the pyrimidine 5-position gave compound 33 (Table 8) [47], which showed modest selectivity for the double mutant over the wild-type kinase.

Encouraged by this finding, the group then went on to explore further lipophilic groups at this position to interact with the gatekeeper methionine, including halogens, $\mathrm{CF}_{3}$, methyl ketone and cyclopropyl [48-51]. Additional SAR was also generated around the nature of the pyrimidine $\mathrm{C} 4$ linker group with an $\mathrm{NH}$ in combination with a $5-\mathrm{CF}_{3}$ group appearing optimal for potency. Broader kinome selectivity (in particular over BTK) was improved by the incorporation of a methoxy group at the 2-position of the aniline. In an attempt to reduce the lipophilicity of the lead compounds, a number of examples were prepared with a basic group appended to the acrylamide warhead, but cell potency tended to be negatively impacted by this change. The addition of a piperazine to the 4-position of the aniline did improve properties and the compounds' in vivo profiles, but wildtype selectivity was reduced and affinity for the hERG ion channel was increased to unacceptable levels. More productive was the move to a morpholine or acylated piperazine at the aniline 4-position, with the reduced $\mathrm{pK}_{\mathrm{a}}$ afforded by these changes removing the hERG liability. This led to the identification of a shortlist of four compounds $(\mathbf{3 4}, \mathbf{3 5}, \mathbf{3 6}, \mathbf{3 7}$, Table 8$)$.

The compounds were all shown to be potent inhibitors in cells of the T790M mutant (Table 8), with compound 37 being selected for further in-depth evaluation, largely based on its excellent wild-type selectivity.

When dosed orally at $100 \mathrm{mg} / \mathrm{kg}$ in an $\mathrm{H} 1975$ mouse tumour xenograft model, 37 (now known as CO-1686 or rociletinib) showed excellent tumour growth inhibition, with partial tumour regressions being evident after 24 days of dosing. In contrast, when dosed in an A431 (EGFR wild-type) tumour growth inhibition study, the compound showed only very modest activity. Rociletinib was licensed by Clovis Oncology Inc. and has shown clinical activity, with responses being evident in some NSCLC T790M positive patients who have progressed on previous EGFR TKI treatment. The compound was relatively well tolerated, with hyperglycaemia the major dose limiting toxicity observed. This is believed to be driven by the potent insulin receptor kinase inhibitory activity of the metabolite 38, derived from in vivo deacylation of rociletinib [52]. Interestingly, responses in T790M negative patients have also been observed, although the reasons behind this are not entirely clear [53]. This may be arfetactual, arising from the heterogeneity of tumours, and that when a biopsy is taken it may sample a T790M negative region of the tumour, whereas the bulk may be T790M positive. Alternatively, the diagnostic test employed may in some cases lack the sensitivity to detect the presence of the T790M mutation and lead to a patient being incorrectly declared T790M negative. It has been reported that the insulin receptor/IGF1R pathway mediates resistance to EGFR inhibitors [54] and there has been some conjecture that the IGF1R kinase inhibitory activity of active metabolite $\mathbf{3 8}$ (Fig. 15) may contribute to activity in this segment. A rolling submission for approval of rociletinib as a second line treatment 


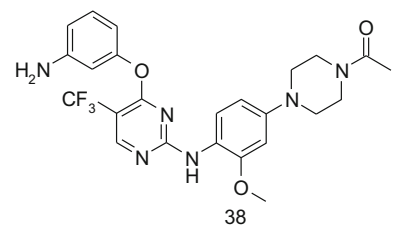

Fig. 15 Structure of rociletinib metabolite 38, which carries potent insulin receptor activity

in NSCLC was made to the FDA in July 2015. However, in November 2015, Clovis announced that as their efficacy data matured, the number of patients with an unconfirmed response who converted to a confirmed response was lower than expected (the current confirmed response rate is 45 percent [53]. In many instances, progression due to brain metastases was noted. However, following an April 2016 FDA Oncologic Drugs Advisory Committee hearing that voted against the accelerated approval of rociletinib and recommended that a randomised Phase III study comparing the compound against single-agent chemotherapy be first completed, Clovis discontinued the development of rociletinib in May 2016.

AstraZeneca was responsible for the discovery of Iressa ${ }^{\mathrm{TM}}$ described above, and with a long-standing interest in the discovery of EGFR inhibitors, also commenced work to discover T790M inhibitors, starting with biochemical testing against the wild-type and T790M double mutant kinases [38]. The initial selection of compounds for testing fell into three classes: reversible anilinoquinazoline-based EGFR inhibitors, irreversible covalent anilinoquinazoline-based EGFR inhibitors and a selection of compounds from previous projects that had been targeting methionine gatekeeper kinases. The anilinoquinazoline-based compounds gave largely the expected inhibition profiles, with the reversibles showing greater activity against wild-type than double mutant, and the covalent compounds showing potent activity against both. However, in contrast to these findings, the methionine gatekeeper targeting examples showed good potency against the T790M mutant as well as selectivity over the wild-type kinase, presumably driven by the preference for the lipophilic pyrimidine 5-substituent of these compounds to interact with the methionine rather than threonine gatekeeper residue. An example of these initial selective hits was compound 39 (Table 9) which originated from AstraZeneca's IGF1R kinase inhibitor project [38].

While compounds such as $\mathbf{3 9}$ did show biochemical potency for the double mutant and selectivity over the wild-type kinase, when tested in a cellular phosphoEGFR assay, a large decrease relative to the isolated enzyme potency was observed (Table 9). This was perhaps not wholly unexpected, given the high affinity of the L858R/T790M double mutant for ATP described above.

In an attempt to circumvent this problem, the team elected to explore covalent targeting of cysteine 797 in an analogous fashion to that described above for afatinib and related compounds. Using a simplified template, which lacked the piperazine group of 39, different potential positions for covalently targeting C797 using an acrylamide motif were explored. This ultimately led to the identification of 
Table 9 Biochemical and cell data for AstraZeneca compounds 39 and $\mathbf{4 0}$
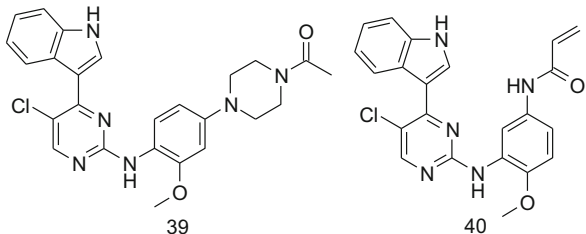

\begin{tabular}{l|l|l|l}
\hline $\begin{array}{l}\text { Compound } \\
\text { number }\end{array}$ & $\begin{array}{l}\text { L858R/T790M enzyme } \\
\mathrm{IC}_{50}(\mu \mathrm{M})\end{array}$ & $\begin{array}{l}\text { H1975 p-EGFR EC } \\
(\mu \mathrm{M})\end{array}$ & $\begin{array}{l}\text { LoVo p-EGFR EC }_{50} \\
(\mu \mathrm{M})\end{array}$ \\
\hline $\mathbf{3 9}$ & 0.009 & 0.77 & 0.77 \\
\hline $\mathbf{4 0}$ & 0.006 & 0.022 & 0.55 \\
\hline
\end{tabular}

H1975 cells (L858R/T790M EGFR), LoVo cells (wild-type EGFR)

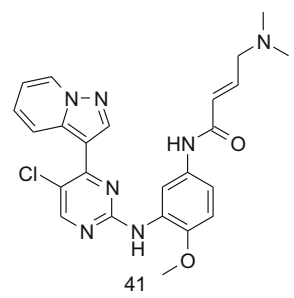

Fig. 16 Structure of compound $\mathbf{4 1}$

inhibitor compound 40 (Table 9), which now showed good potency in the phosphoEGFR cell assay and a selectivity margin to wild-type activity.

Variation of the substituent at the pyrimidine 5-position was then undertaken. This was considered an important position to understand further, as it was speculated that groups here would be oriented towards the kinase gatekeeper residue. In general, double mutant potency was increased by lipophilic groups such as halogens, whereas the sensitising mutant potency remained largely unchanged by these alterations. Efforts were then directed towards reducing the relatively high lipophilicity of the compounds. This was ultimately achieved not only by incorporation of a pendant base on the acrylamide (as had been done with afatinib), but also by alteration of the heterocycle attached at the pyrimidine 4-position. Replacement of the indole moiety with a pyrazolo[1,5-a]pyridine group led to compound $\mathbf{4 1}$ (Fig. 16), which had reduced $\log \mathrm{D}_{7.4}$ and improved physicochemical properties.

Although 41 was not viewed as having clinical candidate quality (due to low aqueous solubility, hERG affinity and IGF1R potency, Table 10), when dosed orally in mouse xenograft studies at $60 \mathrm{mg} / \mathrm{kg}$ for 7 days, it produced significant tumour growth inhibition in both the H1975 (double mutant) and PC9 (sensitising mutant) models. Significantly lower tumour growth inhibition was noted in the A431 (wild-type) model, consistent with the in vitro cell profile. Interestingly, when dosed in the same models at a clinically relevant dose of $6.25 \mathrm{mg} / \mathrm{kg}$ for 7 days, 
Table 10 Data for AstraZeneca probe compound 41

\begin{tabular}{|c|c|c|c|c|c|c|c|c|}
\hline & $\begin{array}{l}\text { PC9 } \\
\text { p-EGFR } \\
\text { EC }_{50} \\
(\mu \mathrm{M})\end{array}$ & $\begin{array}{l}\text { H1975 } \\
\text { p-EGFR } \\
\text { EC }_{50} \\
(\mu \mathrm{M})\end{array}$ & $\begin{array}{l}\text { LoVo } \\
\text { p-EGFR } \\
\text { EC }_{50} \\
(\mu \mathrm{M})\end{array}$ & $\begin{array}{l}\text { hERG } \\
\mathrm{IC}_{50} \\
(\mu \mathrm{M})\end{array}$ & $\begin{array}{l}\text { Solubility } \\
(\mathrm{pH}=7.4)\end{array}$ & $\log D_{7.4}$ & $\begin{array}{l}\% \text { tumour } \\
\text { growth } \\
\text { inhibition } \\
(\mathrm{DM} / \mathrm{SM} / \\
\text { WT) }\end{array}$ & $\begin{array}{l}\text { IGF1R } \\
\text { enzyme } \\
\mathrm{IC}_{50} \\
(\mu \mathrm{M})\end{array}$ \\
\hline 41 & 0.4 & 0.096 & 23 & 4.2 & 1.6 & 3.6 & $105 / 141 / 46$ & 0.004 \\
\hline
\end{tabular}

PC9 cells (exon19 deletion EGFR), H1975 cells (L858R/T790M EGFR), LoVo cells (wild-type EGFR). \% tumour growth inhibition is from a PO dose QD for 7 days at $60 \mathrm{mg} / \mathrm{kg}$

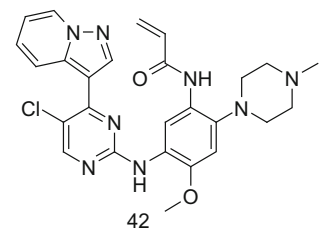

Fig. 17 Structure of compound $\mathbf{4 2}$

Table 11 Data for AstraZeneca compound 43

\begin{tabular}{l|l|l|l|l|l|l}
\hline $\begin{array}{l}\text { PC9 } \text {-EGFR } \\
\mathrm{EC}_{50}(\mu \mathrm{M})\end{array}$ & $\begin{array}{l}\text { H1975 } \\
\text { p-EGFR EC } \\
(\mu \mathrm{M})\end{array}$ & $\begin{array}{l}\text { LoVo p-EGFR } \\
\mathrm{EC}_{50}(\mu \mathrm{M})\end{array}$ & $\begin{array}{l}\text { hERG } \\
\mathrm{IC}_{50} \\
(\mu \mathrm{M})\end{array}$ & $\begin{array}{l}\log _{7.4} \\
(\mu \mathrm{M})\end{array}$ \\
\hline $\mathbf{4 2}$ & 0.14 & 0.019 & 23 & 7.1 & 3.6 & 0.002 \\
\hline
\end{tabular}

PC9 cells (exon19 deletion EGFR), H1975 cells (L858R/T790M EGFR), LoVo cells (wild-type EGFR)

gefitinib showed good activity in the sensitising (142\% tumour growth inhibition) and wild-type models (79\% tumour growth inhibition) but was inactive in the double mutant model, even when dosed as high as $100 \mathrm{mg} / \mathrm{kg} / \mathrm{day}$.

Encouraged by this initial data, the team devised and prepared a series of further analogues based on compound 41. Whilst higher levels of T790M potency were achievable in this template, the structural changes that delivered these improvements always caused increased lipophilicity and compromised physicochemical properties, and it was concluded that these compounds did not have the potential to deliver a cell potent inhibitor with a sufficiently $\operatorname{low} \log \mathrm{D}_{7.4}$ value to deliver acceptable ADMET properties. A way to increase potency without increasing lipophilicity needed to be found. It was apparent from the SAR of reversible analogues that incorporation of a base in the aniline 4-position led to improved biochemical potency with no accompanying increase in $\log \mathrm{D}$. These SAR findings were incorporated into a covalent scaffold, resulting in compound $\mathbf{4 2}$ (Fig. 17), which displayed a highly attractive profile (Table 11).

Compound $\mathbf{4 2}$ was observed to have the same $\log \mathrm{D}_{7.4}$ as $\mathbf{4 1}$ (Table 11), but showed approximately a fourfold increase in double mutant cell potency, 
i.e. increased lipophilicity ligand efficiency (LLE, calculated as the cellular $\mathrm{pIC}_{50}$ minus $\log \mathrm{D}_{7.4}$ ) and further analogues of $\mathbf{4 2}$ were targeted for synthesis, with a focus on further modification and exploration of the basic side chain group.

Three distinct sub-series were designed [55] based on the scaffold of $\mathbf{4 2}$, piperazinyl amides, open chain diamines and cyclic diamine piperazine replacements of varying ring size (Fig. 18).

Whilst the piperazinyl amides such as $\mathbf{4 3}$ were attractive compounds, they were overshadowed by the surprising findings from the other two subseries. The examples where the piperazine ring had been contracted $(44$ and 46) or opened up (45) delivered double mutant cell potent $(<1 \mathrm{nM}$ in the case of $\mathbf{4 5}$ ), wild-type selective inhibitors with good LLE (Table 12). The compounds also had good pharmacokinetic profiles in mouse, and they showed excellent acute biomarker modulation when dosed orally at $10 \mathrm{mg} / \mathrm{kg}$ in mice carrying H1975 or PC9 tumour xenografts.
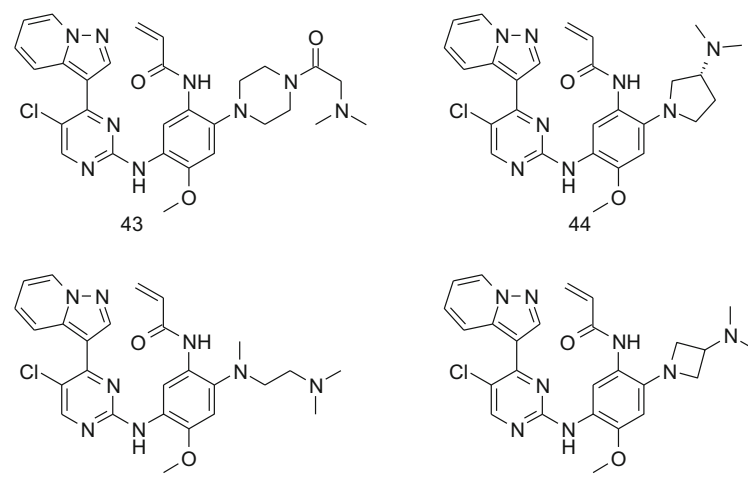

45

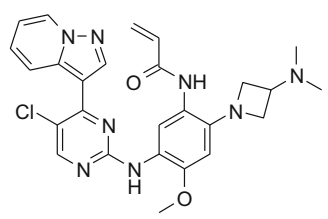

46

Fig. 18 Structures of compounds $43,44,45$ and 46

Table 12 Data for AstraZeneca compound 43, 44, 45 and 46

\begin{tabular}{|c|c|c|c|c|c|c|c|c|}
\hline & $\begin{array}{l}\text { PC9 } \\
\text { p-EGFR } \\
\text { EC }_{50} \\
(\mu \mathrm{M})\end{array}$ & $\begin{array}{l}\text { H1975 } \\
\text { p-EGFR } \\
\text { EC }_{50} \\
(\mu \mathrm{M})\end{array}$ & $\begin{array}{l}\text { LoVo } \\
\text { p-EGFR } \\
\text { EC }_{50} \\
(\mu \mathrm{M})\end{array}$ & $\log _{7.4}$ & $\begin{array}{l}\text { Solubility } \\
(\mu \mathrm{M}, \\
\mathrm{pH}=7.4)\end{array}$ & $\begin{array}{l}\text { \% tumour } \\
\text { growth } \\
\text { inhibition } \\
\text { (DM/SM/ } \\
\text { WT) }\end{array}$ & $\begin{array}{l}\mathrm{hERG} \\
\mathrm{IC}_{50} \\
(\mu \mathrm{M})\end{array}$ & $\begin{array}{l}\text { IGF1R } \\
\text { enzyme } \\
\text { IC50 } \\
(\mu \mathrm{M})\end{array}$ \\
\hline 43 & 0.074 & 0.016 & 10.1 & 2.6 & 290 & - & 18 & 0.002 \\
\hline 44 & 0.016 & 0.002 & 0.357 & 3.1 & 28 & $\begin{array}{l}134 / 227 / \\
27\end{array}$ & 5.6 & 0.007 \\
\hline 45 & 0.002 & 0.0006 & 0.145 & 2.8 & 400 & $\begin{array}{l}130 / 243 / \\
35\end{array}$ & 6.7 & 0.006 \\
\hline 46 & 0.02 & 0.004 & 0.938 & 3.3 & 43 & $\begin{array}{l}113 / 169 / \\
16\end{array}$ & 4.0 & 0.026 \\
\hline
\end{tabular}

PC9 cells (exon19 deletion EGFR), H1975 cells (L858R/T790M EGFR), LoVo cells (wild-type EGFR). \% tumour growth inhibition is from a PO dose QD for 7 days at $10 \mathrm{mg} / \mathrm{kg}$ 
In addition, when tested in the three previously described in vivo tumour models, the compounds all had excellent efficacy at $10 \mathrm{mg} / \mathrm{kg}$ in 7 day studies, with mutant tumour regressions evident, accompanied by very little wild-type activity. The compounds still carried IGF1R activity, reflecting their origins, and hERG affinity was generally less than $10 \mu \mathrm{M}$. Nevertheless, rat and dog PK testing delivered attractive profiles, with dose to man predictions suggesting these compounds might be of candidate quality and consequently $\mathbf{4 4 , 4 5}$ and $\mathbf{4 6}$ were shortlisted as possible clinical candidates.

Given the positive benefits delivered by migration of the base from the acrylamide to the aniline series, in the pyrazolo[1,5-a]pyridine series, the same change was investigated in the original indole series. Consequently, a small library of compounds varying the basic side chain, the pyrimidine 5-position and methylation of the indole head group was explored. A selection of compounds from this work is shown below (Fig. 19).

It was apparent that the ethylene diamine sidechain was the more potent motif and the other groups investigated will not be discussed further. Analysis of matched molecular pairs [55] produced some useful SAR observations. Whilst a lipophilic group at the pyrimidine 5-position drove higher wild-type selectivity and increased IGF1R potency, the impact of its presence or absence on potency was much more pronounced in the latter kinase. In addition, indole methylation was also observed to both increase selectivity over the wild-type kinase and reduce IGF1R potency. These findings offered an opportunity to reduce the IGF1R activity. In the indole series, replacing the 5-chloro group with hydrogen would be predicted to show less IGF1R potency, but also reduced selectivity over wild-type EGFR as well as lower double mutant potency. However, application of the indole SAR described above could suggest a 5-H substituted compound with a suitable overall profile: good potency could be achieved by employing the indole head group combined with the ethylene diamine sidechain and wild-type selectivity could be recovered by employing the methylated indole 4-substituent. The compounds in Table 13 are illustrative of this SAR, with compound 49 displaying a favourable hERG and IGF1R profile, as well as good mutant potency and wild-type kinase selectivity. On
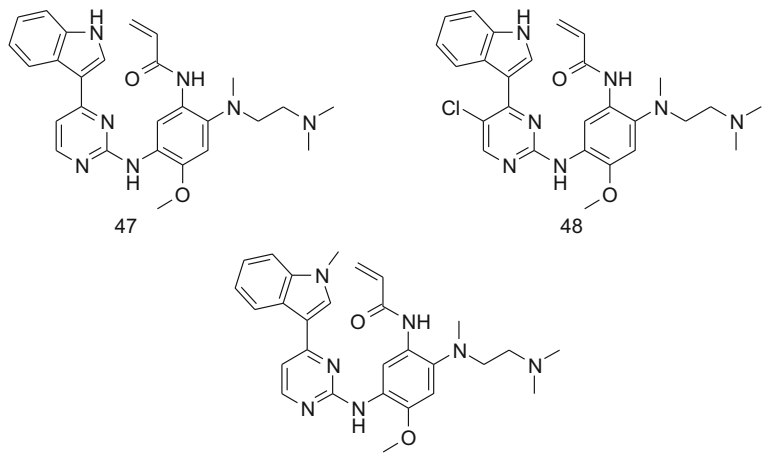

49

Fig. 19 Structures of compounds 47, 48 and $\mathbf{4 9}$ (osimertinib, AZD9291) 
Table 13 Data for AstraZeneca compounds 47, 48 and 49

\begin{tabular}{|c|c|c|c|c|c|c|c|}
\hline & $\begin{array}{l}\text { PC9 } \\
\text { p-EGFR } \\
\text { EC }_{50} \\
(\mu \mathrm{M})\end{array}$ & $\begin{array}{l}\text { H1975 } \\
\text { p-EGFR } \\
\text { EC }_{50} \\
(\mu \mathrm{M})\end{array}$ & $\begin{array}{l}\text { LoVo } \\
\text { p-EGFR } \\
\text { EC }_{50} \\
(\mu \mathrm{M})\end{array}$ & $\begin{array}{l}\text { Mouse PO } \\
\text { AUC/Cmax } \\
(\mu \mathrm{M} h / \mu \mathrm{M})\end{array}$ & $\begin{array}{l}\text { hERG } \\
\mathrm{IC}_{50} \\
(\mu \mathrm{M})\end{array}$ & $\begin{array}{l}\text { IGF1R } \\
\text { enzyme } \\
\mathrm{IC}_{50} \\
(\mu \mathrm{M})\end{array}$ & $\begin{array}{l}\text { \% tumour } \\
\text { growth } \\
\text { inhibition } \\
(\mathrm{DM} / \mathrm{SM} / \mathrm{WT})\end{array}$ \\
\hline 47 & 0.002 & 0.002 & 0.032 & $0.2 / 0.05$ & 17 & 0.026 & - \\
\hline 48 & 0.0002 & 0.0006 & 0.011 & $3.3 / 1.2$ & 15 & 0.007 & - \\
\hline 49 & 0.014 & 0.016 & 0.541 & $1.4 / 0.38$ & 16 & 2.9 & $134 / 242 / 79$ \\
\hline
\end{tabular}

PC9 cells (exon19 deletion EGFR), H1975 cells (L858R/T790M EGFR), LoVo cells (wild-type EGFR). \% tumour growth inhibition is from a PO dose QD for 7 days at $5 \mathrm{mg} / \mathrm{kg}$

the basis of this profile, this compound was advanced into the previously described in vivo efficacy studies, and gratifyingly, it displayed excellent mutant tumour growth inhibition at $10 \mathrm{mg} / \mathrm{kg}$, but now also at the lower oral dose of $5 \mathrm{mpk}$ and indeed lower. With this excellent profile, 49 was also shortlisted for development.

The AstraZeneca researchers were aware that inhibition of IGF1R kinase tends to lead to concomitant inhibition of the insulin receptor, itself possessing a methionine gatekeeper kinase domain. Consequently, the team designed a rat toxicological study to examine this further. Rats received a single oral dose of each compound at $200 \mathrm{mg} / \mathrm{kg}$ and significant compound exposure was achieved in all four cases. Insulin and glucose levels were then monitored. Compounds $\mathbf{4 4}$ and $\mathbf{4 5}$ were caused an almost immediate increase in blood glucose levels, whilst $\mathbf{4 6}$ and $\mathbf{4 9}$ were largely similar to control. When examining the data for insulin, a more sensitive biomarker, $\mathbf{4 4}$ and $\mathbf{4 5}$ elevated insulin levels to a marked extent almost immediately. Compound $\mathbf{4 6}$ was found to have a lower impact on insulin levels, while 49 was indistinguishable from control. These in vivo data showed the same relative trend as the in vitro IGF1R potencies of the four compounds. At this point, it was decided that $\mathbf{4 4}$ and $\mathbf{4 5}$ should not be taken further forward and the compounds were discontinued from further study. Cardiovascular safety assessment of 46 and 49 revealed that 46, when dosed in the guinea pig monophasic action potential study, caused marked QT prolongation. In contrast, even at very high doses 49 was devoid of this effect and as a consequence was selected as clinical candidate AZD9291 (international nonproprietary name osimertinib) [54]. More chronic in vivo tumour growth inhibition studies have been performed with osimertinib in addition to the relatively brief initial studies that were described above [56]. In the PC9 in vivo model (activating mutation, Exon 19 deletion), osimertinib at an oral dose of $5 \mathrm{mg} / \mathrm{kg} /$ day exhibited superior efficacy to gefitinib with tumours being essentially non-palpable by day 40 of the experiment (Fig. 20).

In addition, in a study employing the H1975 cell line (L858R/T790M), a dose of $5 \mathrm{mg} / \mathrm{kg} /$ day showed substantial regression for a 200 day period [56]. Also, a dose of $25 \mathrm{mg} / \mathrm{kg} /$ day orally rendered tumours essentially non-palpable by day 20 and as before this activity was maintained up to the cessation of dosing at day 200. Smaller oral doses of osimertinib (1 mg/kg/day) showed initial activity, which was lost at day 50 , but could be restored by an increase of dose to $25 \mathrm{mg} / \mathrm{kg} / \mathrm{day}$, again 


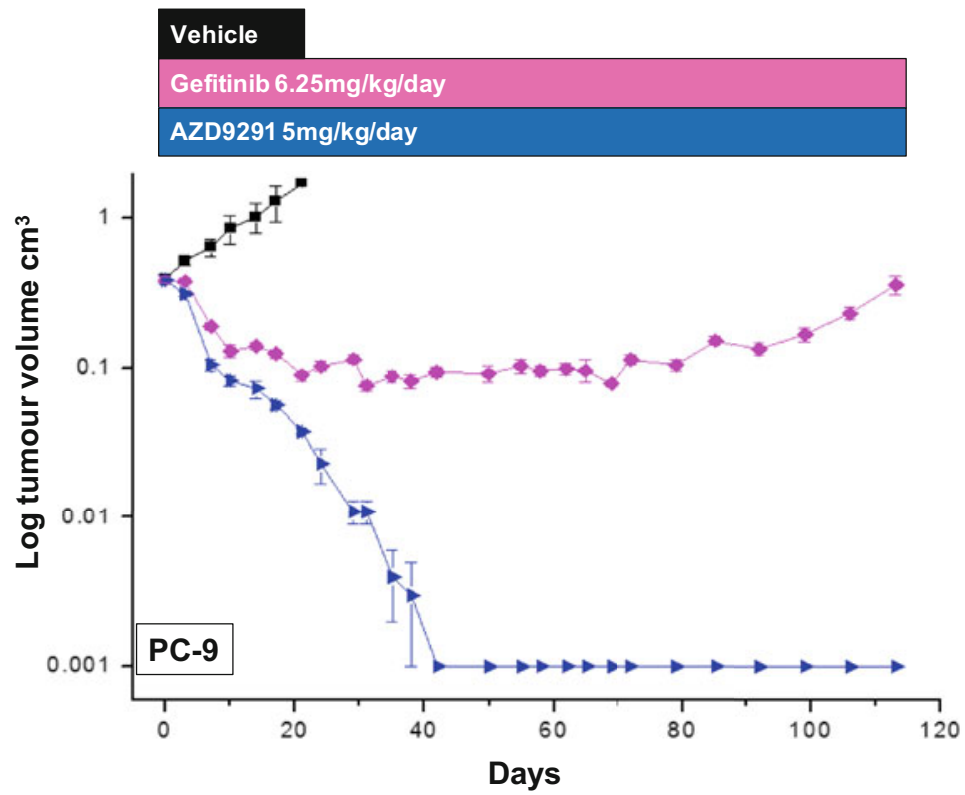

Fig. 20 Mouse in vivo tumour growth inhibition comparison of gefitinib and osimertinib employing PC-9 xenografts. Adapted by permission from the American Association for Cancer Research: Cross et al. [56]

resulting in very significant tumour regression for 200 days. These data are summarised in Fig. 21.

The compound was first dosed to NSCLC patients in March 2013. The initial dose selected for testing was $20 \mathrm{mg}$ and, unusually for a phase I "first into human" study, clinical activity was seen in the very first dose cohort tested [56], enabling rapid acceleration of the clinical program. No maximum tolerated dose was defined during phase I, so the phase II dose was selected based on efficacy and safety data reviewed across the $20-240 \mathrm{mg}$ dose range, with a once-daily $80 \mathrm{mg}$ dose being selected for registration studies. Interestingly, clinical activity with osimertinib has also been anecdotally reported in NSCLC patients presenting with brain metastases and more detailed studies here are ongoing in the clinic [57]. On the 13th of November 2015, osimertinib was granted accelerated approval by the United States FDA "for the treatment of patients with metastatic epidermal growth factor receptor (EGFR) T790M mutation-positive non-small cell lung cancer (NSCLC), as detected by an FDA-approved test, who have progressed on or after EGFR tyrosine kinase inhibitor (TKI) therapy". This approval was based on data from the pre-planned analysis of two clinical trials at the $80 \mathrm{mg}$ QD dose, and osimertinib is now marketed as TAGRISSO ${ }^{\mathrm{TM}}$. A recent disclosure showed an objective response rate (ORR) of $66.1 \%$ in T790M positive patients (Fig. 22) [58]. Further disclosures from this analysis demonstrated a median progression free survival (PFS) of 9.7 months (maturity 39\%). On the 3rd of February 2016, the European Medicines 


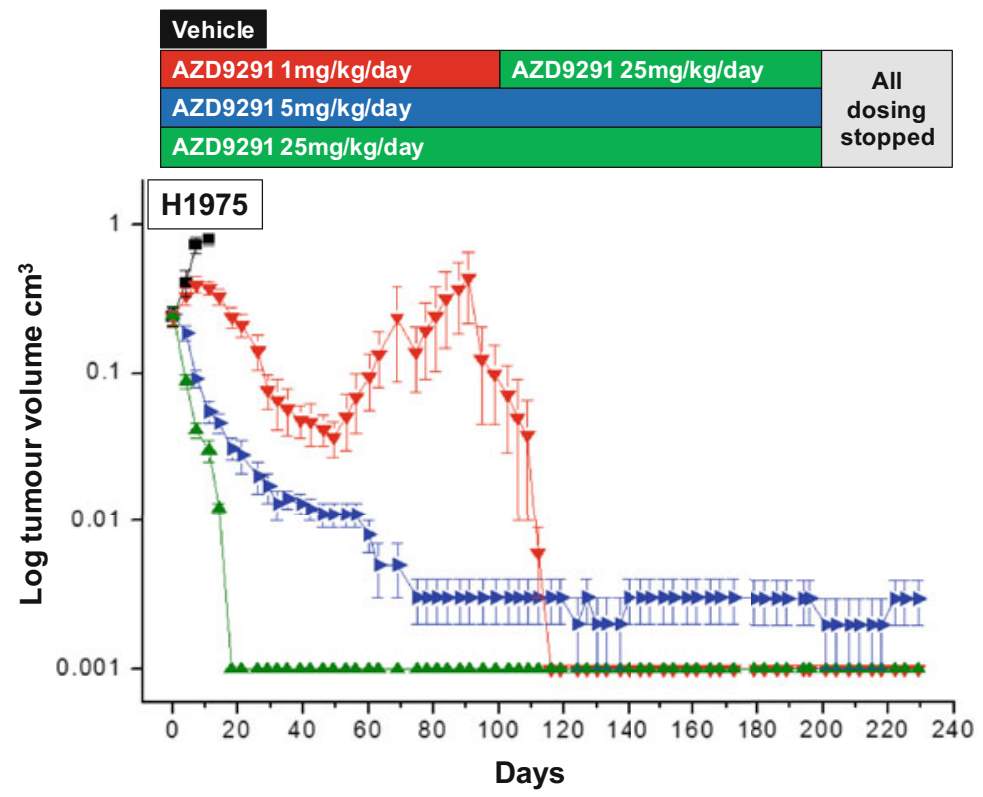

Fig. 21 Mouse in vivo tumour growth inhibition comparison of doses of osimertinib employing H1975 xenografts. Adapted by permission from the American Association for Cancer Research: Cross et al. [56]

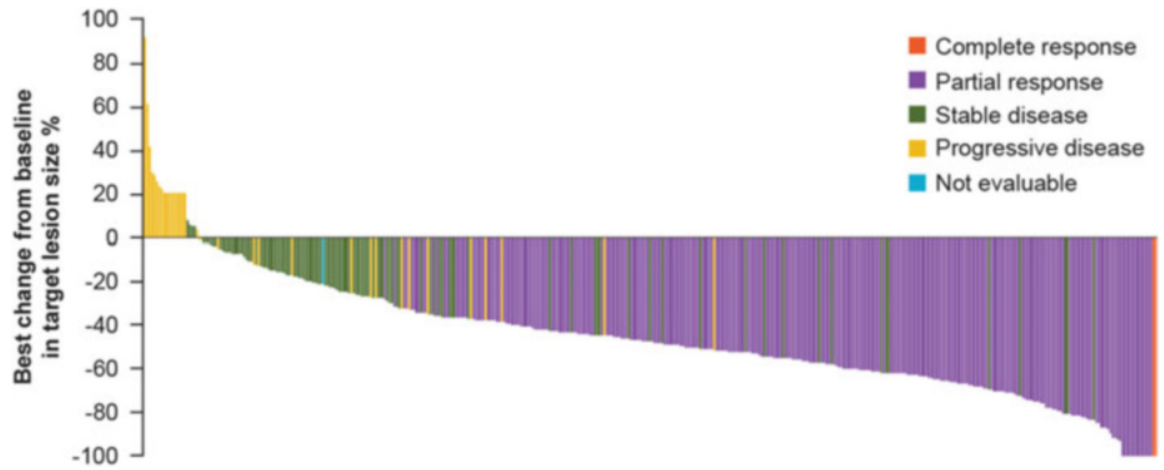

Fig. 22 Osimertinib in pre-treated patients with T790M positive advanced non-small cell lung cancer (NSCLC): pooled analysis. By blinded independent central review. Evaluable for response analysis set $(n=398)$. Mean best percentage change in target lesion size $-45 \%$, standard deviation 28.0 (median best percentage change $-47.6 \%$; range: $-100 \%$ to $+90.8 \%$ ). Adapted from a presentation by Goss [58]

Agency also granted conditional marketing authorisation for TAGRISSO ${ }^{\mathrm{TM}}$ for the treatment of adult patients with locally advanced or metastatic T790M mutationpositive non-small cell lung cancer. Regulatory approval in Japan was also granted in March 2016. 
Additional clinical investigation with osimertinib continues, both in combination with other targeted therapies and as a first line treatment (vide infra).

A number of other mutant selective EGFR inhibitors have recently been disclosed in the literature, and some are now advancing through clinical trials. Data and structures of these compounds (where disclosed) are captured below (Fig. 23), but it is beyond the scope of this chapter to discuss these in any detail. Olmutinib (Olita ${ }^{\mathrm{TM}}$, HM61713, BI1482694, Fig. 23) is now approved in South Korea for patients with EGFR T790M mutation-positive lung cancer, although based on a re-evaluation of available clinical data and recent treatment advances made in EGFRm NSCLC, Boehringer Ingelheim has announced that it has returned development and commercial rights of olmutinib to Hanmi. Taiho Pharma is known to be developing TAS-121 as an oral mutant EGFR selective inhibitor and is currently in Phase 1 clinical trials, but no structure has yet been disclosed. In addition, numerous additional pre-clinical T790M inhibitors have been described in the literature (For example, see: [59-61]).

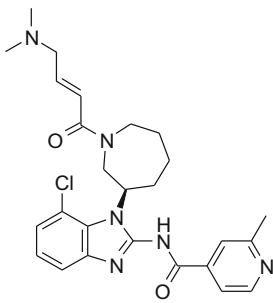

EGF816 (Novartis)<smiles>C=CC(=O)Nc1cccc(O)c1</smiles><smiles>CN1CCN(c2ccc(Nc3nc(O)c4sccc4n3)cc2)CC1</smiles>

HM61713, olmutinib, BI1482694 (Hanmi Pharmaceutical Co.) Was licensed to Boehringer Ingelheim, but now returned to Hanmi

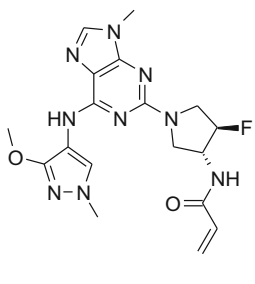

PF-06747775 (Pfizer)

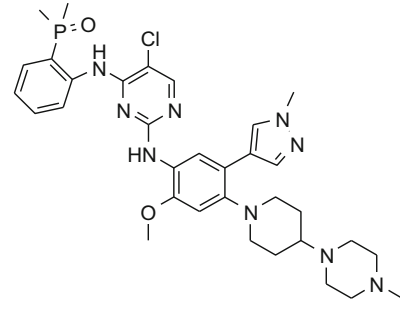

AP26113, brigatinib (Ariad Pharmaceuticals)

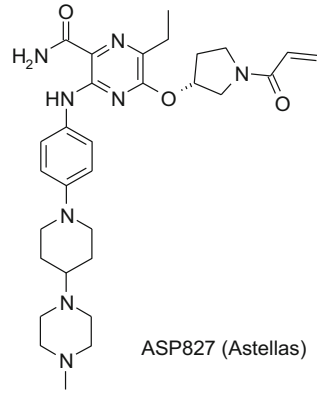

${ }^{\mathrm{O} H}$

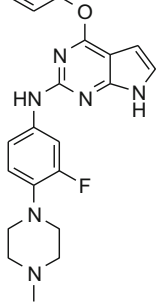

AC0010, avitinib, (Acea Biosciences)

Fig. 23 Structures of Novartis, Pfizer, Astellas, Hanmi, Ariad and Acea clinical mutant selective EGFR inhibitors 


\section{Future Perspectives}

The progress in identifying and developing EGFR inhibitors over the past three decades has been remarkable and has resulted in clear and meaningful benefit to NSCLC patients. Also noteworthy is the growth in knowledge and understanding of the area, moving from broadly targeted use of inhibitors with mixed results, to more clearly understanding the significance of sensitising mutations and the role of the wild-type receptor in driving toxicity. The emergence of the EGFR T790M resistance mutation prompted a flurry of discovery activity and patients are now starting to see the benefits of these endeavours. It is likely that resistance in the clinic will again emerge to these treatments as tumour cells continue to evolve mechanisms to evade their effects, and indeed in the case of osimertinib, a C797S "triple mutant" (removing the possibility of covalent bond formation to osimertinib) has been observed in some patients who have progressed on this treatment [62]. In the case of rociletinib, clinical resistance has been observed in a variety of forms including re-emergence of the T790 wild-type protein, and EGFR amplification [63]. However, with much greater understanding now at their disposal, clinicians and pre-clinical scientists are able to more quickly explore ways to circumvent the next resistance mechanism. Further research has shown that in addition to EGFR mutations, other signalling pathways (MET [64] and see also Cross et al. [56], MEK [65]) can also be upregulated in response to EGFR inhibitor treatment and the combination of an EGFR inhibitor with a compound to inhibit these pathways may have clinical potential. In the past such combinations were challenging due to the toxicity burden imposed by the two combined agents. However, the wild-type margin and improved tolerability of agents such as osimertinib and olmutinib now makes these combination opportunities more attractive, and such studies are currently ongoing in the clinic $[66,67]$. Whilst compounds such as rociletinib and osimertinib have been extensively studied as second line treatments in patients who have progressed following gefitinib or erlotinib therapy, in the case of osimertinib, use as a first line treatment in TKI naïve patients has also recently shown very encouraging clinical activity. In 60 patients who received osimertinib once daily at either 80 or $160 \mathrm{mg}$, the median progression-free survival (PFS) was 19.3 months, and the confirmed objective response rate (ORR) was 77\% [68]. Further data for osimertinib in this setting is awaited. The EGFR inhibitor landscape continues to evolve and challenge the research community, but it is likely that the target will continue to provide both scientific challenges and patient benefit for a considerable time to come. 


\section{References}

1. Stewart BW, Wild CP (eds) (2014) World cancer report 2014. International Agency for Research on Cancer, Lyon

2. Normanno N, De Luca A, Bianco C, Strizzi L, Mancino M, Maiello MR, Carotenuto A, De Feo G, Caponigro F, Salomon DS (2006) Gene 366:2-16

3. Schneider MR, Wolf E (2009) J Cell Physiol 218:460-466

4. Baselga J (2002) Oncologist 7(Suppl 4):2-8

5. Ward WHJ, Cook PN, Slater AM, Davies DH, Holdgate GA, Green LR (1994) Biochem Pharmacol 48:659-666

6. Barker AJ, Davies DH, Imperial Chemical Industries PLC (1992) Preparation of 4-anilinoquinazolines as neoplasm inhibitors. EP 520722 A1 19921230

7. Barker AJ, Zeneca Ltd. (1993) Quinazoline tyrosine kinase-inhibiting anticancer agents. CA 2086968 A1 19930721

8. Bridges AJ (2001) Chem Rev 101:2541-2571

9. Barker AJ, Gibson KH, Grundy W, Godfrey AA, Barlow JJ, Helay MP, Woodburn JR, Ashton SE, Curry BJ, Scarlett L, Henthorn L, Richards L (2001) Bioorg Med Chem Lett 11:19111914

10. Wakeling AE, Guy SP, Woodburn JR, Ashton SE, Curry BJ, Barker AJ, Gibson KH (2002) Cancer Res 62:5749-5754

11. Rewcastle GW, Denny WA, Bridges AJ, Zhou H, Cody DR, McMichael A, Fry DW (1995) J Med Chem 38:3482-3487

12. Denny WA, Rewcastle GW, Bridges AJ, Fry DW, Kraker AJ (1996) Clin Exp Pharmacol Physiol 23:424-427

13. Woodburn JR, Barker AJ, Gibson KH, Ashton SE, Wakeling AE, Curry BJ, Scarlett L, Henthorn LR (1997) In: Proceedings of the 88th annual meet, AACR 1997, vol 38, Abstract 4251

14. Basalga J, LoRusso P, Herbst R, Rischin D, Ranson M, Maddox A-M, Feyereislova A, Averbuch S (1999) In: Proceedings of the AACR-NCIEORTC international conference 1999, Abstract 29

15. Kris M, Ranson M, Ferry D, Hammond L, Averbuch S, Ochs J, Rowinsky E (1999) In: Proceedings of the AACR-NCI-EORTC international conference 1999, Abstract 99

16. Baselga J, Averbuch SD (2000) Drugs 60:33

17. Arnold LD, Schnur RC. WO1996030347

18. Moyer JD, Barbacci EG, Iwata KK, Arnold L, Boman B, Cunningham A, DiOrio C, Doty J, Morin MJ, Moyer MP, Neveu M, Pollack VA, Pustilnik LR, Reynolds MM, Sloan D, Theleman A, Miller P (1997) Cancer Res 57:4838

19. Pollack VA, Savage DM, Baker DA, Tsaparikos KE, Sloan DE, Moyer JD, Barbacci EG, Pustilnik LR, Smolarek TA, Davis JA, Vaidya MP, Arnold LD, Doty JL, Iwata KK, Morin MJ (1999) J Pharmacol Exp Ther 291:739

20. Siu LL, Hidalgo M, Nemunaitis J, Rizzo J, Moczygemba J, Eckhardt SG, Tolcher A, Smith L, Hammond L, Blackburn A, Tensfeldt T, Silberman S, Von Hoff DD, Rowinsky EK (1999) In: Proceedings of the 35th annual meet, ASCO 1999, vol 18, 388a Abstract 1498

21. Karp DD, Silberman SL, Tensfeldt T, Csudae R, Wirth F, Gaynes L, Posner M, Bubley G, Koon H, Bergman M, Pandya S, Schnipper LE (1999) In: Proceedings of the 35th annual meet, ASCO 1999, vol 18, 388a Abstract 1499.

22. Barf T, Kaptein AJ (2012) Med Chem 55:6243-6262

23. Liu Q, Sabnis Y, Zhao Z, Zhang T, Buhrlage SJ, Jones LH, Gray NS (2013) Chem Biol 20:146-159

24. Clark S, Konstantopoulos N (1993) Biochem J 292:217-223

25. Woltjer RL, Staros JV (1997) Biochemistry 36:9911-9916

26. Singh J, Dobrusin EM, Fry DW, Haske T, Whitty A, McNamara DJJ (1997) Med Chem 40:1130-1135 
27. Fry DW, Bridges AJ, Denny WA, Doherty A, Gries KD, Hicks JL, Hook KE, Keller PR, Leopold WR, Loo JA, McNamara DJ, Nelson JM, Sherwood V, Smaill JB, TrumppKallmeyer S, Dobrusin EM (1998) Proc Natl Acad Sci U S A 95:12022-12027

28. Smaill JB, Palmer BD, Rewcastle GW, Denny WA, McNamara DJ, Dobrusin EM, Bridges AJ, Zhou H, Showalter HDH, Winters RT, Leopold WR, Fry DW, Nelson JM, Slintak V, Elliot WL, Roberts BJ, Vincent PW, Patmore SJ (1999) J Med Chem 42:1803-1815

29. Smaill JB, Rewcastle GW, Loo JA, Greis KD, Chan H, Reyner EL, Lipka E, Hollis Showalter HD, Vincent PW, Elliott WL, Denny WA (2000) J Med Chem 43:1380-1397

30. Wissner A, Johnson BD, Floyd MB, Kitchen DB (1998) US Pat. 5,760,041

31. Discafani CM, Carroll ML, Floyd MB, Hollander IJ, Husain Z, Johnson BD, Kitchen D, May MK, Malo MS, Minnick AA, Nilakantan R, Shen R, Wang YF, Wissner A, Greenberger LM (1999) Biochem Pharmacol 57:917

32. Wissner A, Overbeek E, Reich MF, Floyd MB, Johnson BD, Mamuya N, Rosfjord EC, Discafani C, Davis R, Shi X, Rabindran SK, Gruber BC, Ye F, Hallett WA, Nilakantan R, Shen R, Wang YF, Greenberger LM, Tsou HRJ (2003) Med Chem 46:49-63

33. Engelman JA, Zejnullahu K, Gale C-M, Lifshits E, Gonzales AJ, Shimamura T, Zhao F, Vincent PW, Naumov GN, Bradner JE, Althaus IW, Ghandi L, Shapiro GI, Nelson JM, Heymach JV, Meyerson M, Wong K-K, Janne PA (2007) Cancer Res 67:11924-11932

34. Brzezniak C, Carter CA, Giaccone G (2013) Expert Opin Pharmacother 14:247-253

35. Li D, Ambrogio L, Shimamura T, Kubo S, Takahashi M, Chirieac LR, Padera RF, Shapiro GI, Baum A, Himmelsbach F, Rettig WJ, Meyerson M, Solca F, Greulich H, Wong K-K (2008) Oncogene 27:4702-4711

36. Lin NU, Winer EP, Wheatley D, Carey LA, Houston S, Mendelson D, Munster P, Frakes L, Kelly S, Garcia AA, Cleator S, Uttenreuther-Fischer M, Jones H, Wind S, Vinisko R, Hickish T (2012) Breast Cancer Res Treat 133:1057-1065

37. Sharma SV, Bell DW, Settleman J, Haber DA (2007) Nat Rev Cancer 7:169-181

38. Ward RA, Anderton MJ, Ashton S, Bethel PA, Box M, Butterworth S, Colclough N, Chorley CG, Chuaqui C, Cross DA, Dakin LA, Debreczeni JE, Eberlein C, Finlay MRV, Hill GB, Grist M, Klinowska TC, Lane C, Martin S, Orme JP, Smith P, Wang F, Waring MJ (2013) J Med Chem 56:7025-7048

39. Pines G, Köstler WJ, Yarden Y (2010) FEBS Lett 584:2699-2706

40. Yun C, Mengwasser KE, Toms AV, Woo MS, Greulich H, Wong K, Meyerson M, Eck MJ (2008) Proc Natl Acad Sci U S A 105:2070-2075

41. Johnston JB, Navaratnam S, Pitz MW, Maniate JM, Wiechec E, Baust H, Gingerich J, Skliris GP, Murphy LC, Los M (2006) Curr Med Chem 13:3483-3492

42. Kobayashi S, Boggon TJ, Dayaram T, Jaenne PA, Kocher O, Meyerson M, Johnson BE, Eck MJ, Tenen DG, Halmos B (2005) N Engl J Med 352:786-792

43. Yun C, Woo MS, Greulich H, Meyerson M, Eck MJ, Wong K (2008) 236th national meeting of the American Chemical Society, Philadelphia, PA, Aug 17-21, 2008. American Chemical Society, Washington; COMP 373

44. Sos ML, Rode HB, Heynck S, Peifer M, Fischer F, Klüter S, Pawar VG, Reuter C, Heuckmann JM, Weiss J, Ruddigkeit L, Rabiller M, Koker M, Simard JR, Getlik M, Yuza Y, Chen T-H, Greulich H, Thomas RK, Rauh D (2010) Cancer Res 70:868-874

45. Zhou W, Ercan D, Chen L, Yun C, Li D, Capelletti M, Cortot AB, Chirieac L, Iacob RE, Padera R, Engen JR, Wong K, Eck MJ, Gray NS, Janne PA (2009) Nature 462:1070-1074

46. Singh J, Evans E, Hagel M, Labinski M, Dubrovskiy A, Nacht M, Petter RC, Prasad A, Sheets M, St Martin T, Sjin RTT, Westlin W, Zhu Z (2012) Med Chem Commun 3:780

47. Kluge AF, Petter RC, Tester RW, Qiao L, Niu D, Westlin WF, Singh J, Mazdiyasni H. WO2009158571

48. Baevsky MF, Lee K, Niu D, Petter RC, Singh J. WO2012061299

49. Sjin RTT, Lee K, Walter AO, Dubrovskiy A, Sheets M, St. Martin T, Labenski T, Zhu Z, Tester R, Karp R, Medikonda A, Chaturvedi P, Ren Y, Haringsma H, Etter J, Raponi M, Simmons AD, Harding TC, Niu D, Nacht M, Westlin WF, Petter RC, Allen A, Singh J (2014) Mol Cancer Ther 13:1468-1479 
50. Walter AO, Sjin RTT, Haringsma HJ, Ohashi K, Sun J, Lee K, Dubrovskiy A, Labenski M, Zhu Z, Wang Z, Sheets M, St Martin T, Karp R, van Kalken D, Chaturvedi P, Niu D, Nacht M, Petter RC, Westlin W, Lin K, Jaw-Tsai S, Raponi M, Van Dyke T, Etter J, Weaver Z, Pao W, Singh J, Simmons AD, Harding TC, Allen A (2013) Cancer Discov 3:1404-1415

51. Niu D (2008) 250th national meeting of the American Chemical Society, Boston, MA, Aug 16-20, 2015. American Chemical Society, Washington; MEDI 337

52. Soria JC (2014) In: 26th EORTC-NCI-AACR symposium on molecular targets and therapeutics, Barcelona, 18-21 Nov 2014

53. Sequist LV, Soria J-C, Camidge DR (2016) N Engl J Med 374:2296-2297

54. Lee Y, Wang Y, James M, Jeong JH, You M (2015) Mol Carcinog. doi:10.1002/mc.22342

55. Finlay MRV, Anderton M, Ashton S, Ballard P, Bethel PA, Box MR, Bradbury RH, Brown SJ, Butterworth S, Campbell A, Chorley C, Colclough N, Cross DAE, Currie GS, Grist M, Hassall L, Hill GB, James D, James M, Kemmitt P, Klinowska T, Lamont G, Lamont SG, Martin N, McFarland HL, Mellor MJ, Orme JP, Perkins D, Perkins P, Richmond G, Smith P, Ward RA, Waring MJ, Whittaker D, Wells S, Wrigley GL (2014) J Med Chem 57:8249-8267

56. Cross DAE, Ashton SE, Ghiorghiu S, Eberlein C, Nebhan CA, Spitzler PJ, Orme JP, Finlay MRV, Ward RA, Mellor MJ, Hughes G, Rahi A, Jacobs VN, Brewer MR, Ichihara E, Sun J, Jin H, Ballard P, Al-Kadhimi K, Rowlinson R, Klinowska T, Richmond GHP, Cantarini M, Kim D-W, Ranson MR, Pao W (2014) AZD9291, an irreversible EGFR TKI, overcomes T790M-mediated resistance to EGFR inhibitors in lung cancer. Cancer Discov 4:1046-1061

57. Kim D-W, Ahn M-J, Lee DH, Cho BC, Lee JS, Ye X, Yang P, Jiang H, Yang JC-H (2015) In: AACR-NCI-EORTC international conference on molecular targets and cancer therapeutics, Boston, 5-9 Nov 2015

58. Goss GD, Yang JCH, Ahn M, Tsai CM, Bazhenova L, Sequist LV, Ramalingam SS, Shepherd FA, Ghiorghiu S, Cantarini M, Mann H, Mitsudomi T, Jänne PA (2015) AZD9291 in pre-treated patients with T790M positive advanced non-small cell lung cancer (NSCLC): pooled analysis from two phase II studies [abstract no. 3113 plus poster]. In: European Cancer Congress, 2015

59. Heald R, Bowman KK, Bryan MC, Burdick D, Chan B, Chan E, Chen Y, Clausen S, Dominguez-Fernandez B, Eigenbrot C, Elliott R, Hanan EJ, Jackson P, Knight J, La H, Lainchbury M, Malek S, Mann S, Merchant M, Mortara K, Purkey H, Schaefer G, Schmidt S, Seward E, Sideris S, Shao L, Wang S, Yeap K, Yen I, Yu C, Heffron TP (2015) J Med Chem 58:8877-8895

60. Wurz RP, Pettus LH, Ashton K, Brown J, Chen JJ, Herberich B, Hong F-T, Hu-Harrington E, Nguyen T, St. Jean Jr DJ, Tadesse S, Bauer D, Kubryk M, Zhan J, Cooke K, Mitchell P, Andrrws KL, Hsieh F, Hickman D, Kalyanaraman N, Wu T, Reid DL, Lobenhofer EK, Andrews DA, Everds N, Guzman R, Parsons AT, Hedley SJ, Tedrow J, Thiel OR, Potter M, Radinsky R, Beltran PJ, Tasker AS (2015) ACS Med Chem Lett 6:987-992

61. Chan S, Han K, Qu R, Tong L, Li Y, Zhang Z, Cheng H, Lu X, Patterson A, Smaill J, Ren X, Ding J, Xie H, Ding K (2015) Bioorg Med Chem Lett 25:4277-4281

62. Thress KS, Paweletz CP, Felip E, Cho BC, Stetson D, Dougherty B, Lai Z, Markovets A, Vivancos A, Kuang Y, Ercan D, Matthews SE, Cantarini M, Barrett JC, Janne PA, Oxnard GR (2015) Nat Med 21:560-562

63. Piotrowska Z, Niederst MJ, Karlovich CA, Wakelee HA, Neal JW, Mino-Kenudson M, Fulton L, Hata AN, Lockerman EL, Kalsy A, Digumarthy S, Muzikansky A, Raponi M, Garcia AR, Mulvey HE, Parks MK, DiCecca RH, Dias-Santagata D, Iafftae AJ, Shaw AT, Allen AR, Engelman JA, Sequist LV (2015) Cancer Discov 5:713-722

64. Planchard D, Loriot Y, Andre F, Gobert A, Lacroix L, Soria JC (2015) Ann Oncol 26:20732078

65. Eberlein CA, Stetson D, Markovets AA, Al-Kadhimi KJ, Lai Z, Fisher PR, Meador CB, Spitzler P, Ichihara E, Ross SJ, Ahdesmaki MJ, Ahmed A, Ratcliffe LE, Obrien EL, Barnes CH, Brown H, Smith PD, Dry JR, Beran G, Thress KS, Dougherty B, Pao W, Cross DA (2015) Cancer Res 75:2489-2500 
66. Oxnard GR, Ramalingam SS, Ahn M-J, Kim S-W, Yu HA, Saka H, Horn L, Goto K, Ohe Y, Cantarini M, Frewer P, Lahn M, Yang JC-H (2015) J Clin Oncol 33. Suppl; abstract 2509

67. Simmons AD, Haringsma HJ, Nguyen M, Robillard L, Allen A, Harding TC (2015) In: 16th world conference on lung cancer, Denver CO, 6-9 Sept 2015, Abstract 3010

68. Ramalingam SS, Yang JC-H, Lee CK, Kurata T, Kim D-W, John T, Nogami N, Ohe Y, Janne PA (2016) J Thorac Oncol 11(Suppl):S152 